\title{
Intercomparison of stratospheric ozone and temperature measurements at the Observatoire de Haute Provence during the OTOIC NDSC validation campaign from 1-18 July 1997
}

G. O. Braathen ${ }^{1}$, S. Godin-Beekmann ${ }^{2}$, P. Keckhut ${ }^{2}$, T. J. McGee ${ }^{3}$, M. R. Gross ${ }^{4}$, C. Vialle ${ }^{2}$, and A. Hauchecorne ${ }^{2}$

${ }^{1}$ Norwegian Institute for Air Research, Kjeller, Norway

${ }^{2}$ Service d'Aéronomie, Centre National de la Recherche Scientifique, Verrières-le-Buisson, France

${ }^{3}$ Laboratory for Atmospheres, NASA Goddard Space Flight Center, Greenbelt, Maryland, USA

${ }^{4}$ Joint Center for Earth-Systems Technology, University of Maryland, Baltimore, USA

Received: 18 June 2004 - Accepted: 12 August 2004 - Published: 10 September 2004

Correspondence to: G. O. Braathen (geir@nilu.no)

Intercomparison of stratospheric ozone and temperature measurements

G. O. Braathen et al.

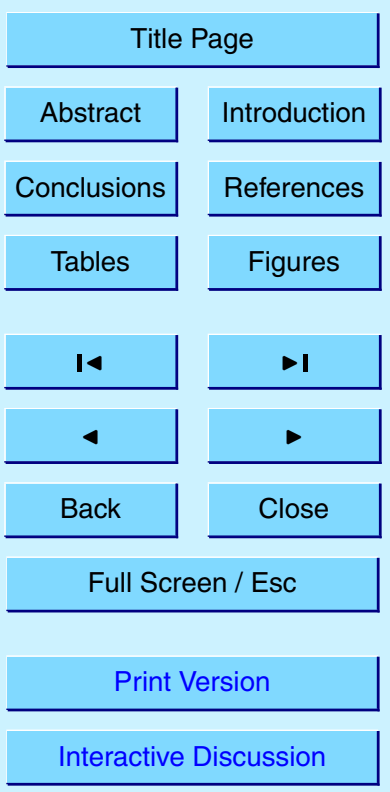




\section{Abstract}

The OHP Temperature and Ozone Intercomparison Campaign (OTOIC) took place at the Observatoire de Haute Provence, France, from 1-18 July 1997. The NASA Goddard Space Flight Center (GSFC) mobile lidar system was deployed at the Observa5 toire de Haute Provence (OHP) during a blind intercomparison as a part of the continuous validation process within the Network for the Detection of Stratospheric Change. The GSFC measurements were compared to two lidars permanently deployed at OHP and operated by the Centre National de la Recherche Scientifique (CNRS), one measuring ozone and the other measuring temperature.

\section{Introduction}

During a workshop in 1986 the idea of a network of high-quality remote sounding instruments was born. In the following years, new instruments were developed and permanent sites were established. In January 1991 the international Network for the Detection of Stratospheric Change (NDSC, http://www.ndsc.ws)(Kurylo and Solomon, 15 1990) became operational. The network consists of a limited number of so-called primary sites and a larger and still growing number of auxiliary sites. There are seven primary stations: one polar, mid-latitude and tropical in each hemisphere and one near the equator. Each of the primary stations are equipped with a large range of instruments to provide collocated measurements of most of the parameters and chemical species involved in stratospheric ozone chemistry. In some cases a station consists of several sites within a relatively small region. This is the case with the mid-latitude station in the Northern Hemisphere, the so-called Alpine station, which consists of Bern and Jungfraujoch in Switzerland, Garmisch-Partenkirchen and Zugspitze in Germany, and Observatoire de Haute Provence (OHP), Plateau de Bure and the Observatoire de
ACPD

4, 5303-5344, 2004

Intercomparison of stratospheric ozone and temperature measurements

G. O. Braathen et al.

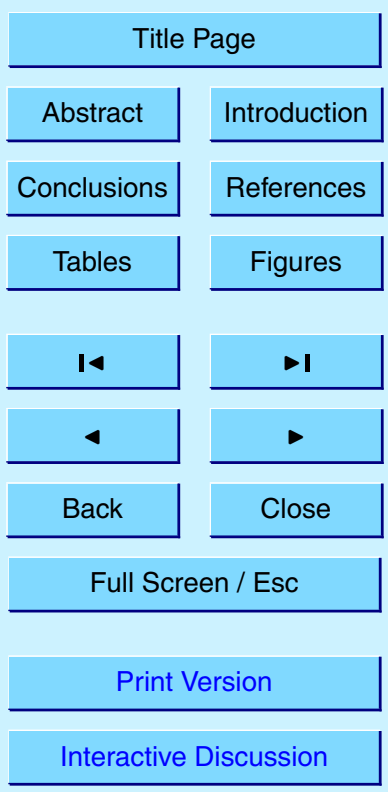

(C) EGU 2004 
paigns. Two of the key measurements within the NDSC are temperature and ozone.

Ozone is of course the single most important component to be measured and for long term trend studies it is important that the different stations constitute a homogeneous network.

5 The temperature is also a very important parameter as it control the rates of chemical reactions and hence ozone abundance. Several of the last Arctic winters have demonstrated clearly how sensitive the ozone amount is to the temperature conditions. Since the temperatures in the Arctic winter stratosphere oscillate around the existence temperature for type I polar stratospheric clouds (PSCs) only small variations in the 10 temperature can lead to large variations in the degree of chlorine and bromine activation. In winters with long periods of PSC temperatures one has observed substantial chemical ozone loss. This was observed in 1993, 1995, 1996, 1997 and 2000 (Hansen et al., 1998; Rex et al., 1997). The relatively milder winters of 1992, 1994, 1998 and 1999 experienced less ozone loss (Schulz et al., 2001)

15 The increasing amount of $\mathrm{CO}_{2}$, methane, $\mathrm{H}_{2} \mathrm{O}$ and other greenhouse gases is also a matter of concern. Increased concentration of greenhouse gases will lead to decreasing temperatures in the stratosphere and hence a higher risk of activation of the halogenated reservoir gases through reactions on PSCs. Model calculations that take into consideration the cooling effect of greenhouse gases in the stratosphere conclude that one can expect serious ozone loss, with minimum total ozone values in March down to 120 Dobson Units during the decade from 2010 to 2019 (Shindell et al., 1998).

Instrument validation is an essential exercise in the operation of the NDSC. Previous NDSC lidar intercomparisons include the Stratospheric Ozone Intercomparison Campaign (STOIC) in 1989 (Komhyr et al., 1995; Margitan et al., 1995; McDermid et al., 1995; McGee et al., 1995a), the Ozone Profiler at Lauder (OPAL)(McDermid et al., 1998) and the Mauna Loa Ozone campaigns in 1995 (McDermid et al., 1999; McPeters et al., 1998). In 1998 there was an intercomparison between the GSFC mobile lidar and the ozone lidar of the Alfred Wegener Institute in Ny-Ålesund, Spitsbergen (Steinbrecht et al., 1999).
ACPD

4, 5303-5344, 2004

Intercomparison of

stratospheric ozone and temperature measurements

G. O. Braathen et al.

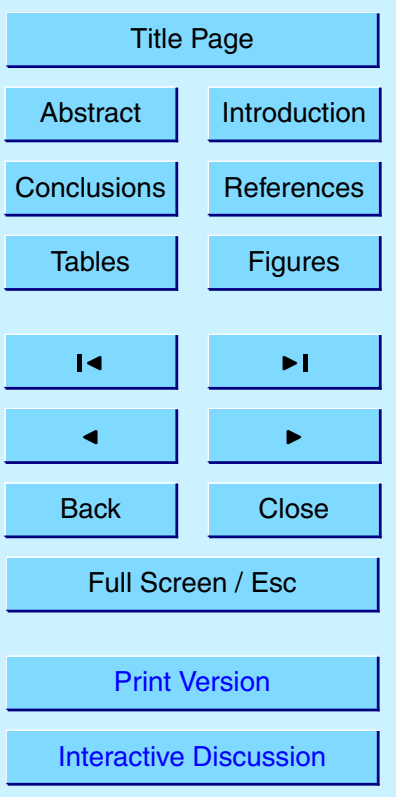

(C) EGU 2004 
At the Observatory of Haute-Provence (OHP), two stratospheric lidars (for ozone and temperature) have been run routinely before the NDSC was formally initiated. The two lidars have provided some of the longest stratospheric lidar data sets reaching back to 1979 and 1986, respectively for temperature and ozone. These data sets have already 5 been used for preliminary trend estimates (Hauchecorne et al., 1991; Keckhut et al., 1995; Guirlet et al., 2000). These two lidar systems were already intercompared with the NASA Goddard Space Flight Center lidar in July of 1992. At that time, a large amount of volcanic aerosols had been ejected into the stratosphere due to the Mount Pinatubo eruption in June 1991, and most of the measurements were disturbed by

10 this unusual amount of particles. During this campaign, the Raman channels were implemented and tested for the first time allowing this technique to be insensitive to stratospheric particles (McGee et al., 1993). Since then, several modifications and improvements have been implemented on all the three lidars.

\section{Instruments, algorithms and experiment}

\section{2.1. GSFC lidar}

\subsubsection{Description of the GSFC lidar system}

The GSFC mobile lidar was shipped to OHP in the summer of 1997. The generatorpowered lidar system is housed in a 45 -foot trailer. The GSFC lidar system, designed primarily for measuring stratospheric ozone using the differential absorption lidar (DIAL) technique, has been modified in recent years (McGee et al., 1991, 1993, 1995).

$\mathrm{A} \mathrm{XeCl}$ excimer laser provides radiation at $307.9 \mathrm{~nm}$, which is absorbed by ozone, and a XeF laser emitting at $351 \mathrm{~nm}$ is used as the atmospheric reference. Elastic backscatter returns, and Raman backscatter returns from $\mathrm{N}_{2}$ are retrieved for each of the transmitted laser wavelengths. The elastic returns are further split into low and high

ACPD

4, 5303-5344, 2004

Intercomparison of stratospheric ozone and temperature measurements

G. O. Braathen et al.

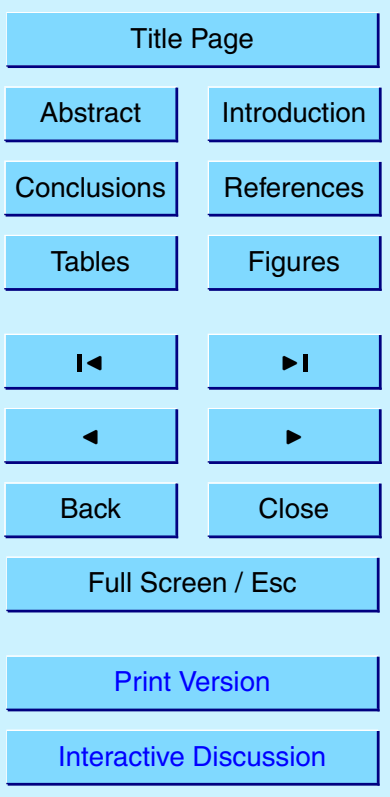

(C) EGU 2004 
sensitivity detectors. Used together with the DIAL technique, these wavelengths permit the extraction of ozone profiles between 10 and $50 \mathrm{~km}$.

The Rayleigh return at $351 \mathrm{~nm}$ can be processed to give temperature and density profiles between 30 and $70 \mathrm{~km}$. The elastic return along with two additional $\mathrm{N}_{2}$ Raman 5 scattering returns can be used for computing aerosol scattering ratio, aerosol backscatter, and aerosol extinction profiles. When the aerosol layer approaches the background levels, the Raman backscattering signal can also be used to retrieve the temperature down to $10 \mathrm{~km}$. The details of the system modifications, improvements and capabilities are described by (McGee et al., 1995b).

\subsubsection{Algorithm}

The GSFC lidar typically acquires data from $10^{6}$ laser shots, corresponding to an integration time of roughly $84 \mathrm{~min}$ at the $200 \mathrm{~Hz}$ pulse repetition frequency of the excimer lasers. An experimentally determined, dead-time correction to the lidar returns is applied to all six of the individual data channels. The use of the mechanical chopper for both the 308 and $351 \mathrm{~nm}$ high sensitivity channels has removed the necessity of fitting the background data to a function in order to estimate the background. With this configuration, we have seen no evidence for signal-induced-noise in these channels. The $308 \mathrm{~nm}$ low channel has sometimes shown evidence of such noise, and this is removed by treating the background as an exponential function. The effect of such SIN on ozone retrieved from the low $308 \mathrm{~nm}$ channel, is very small at the altitudes used, even when such correction is not applied.

Ozone is extracted from the lidar data in the following way. First, the ratio of the absorbed to non-absorbed returns is formed. At each point in the resulting ratio, the derivative is taken, and this derivative can be directly related to ozone concentration. mathematically identical to the derivative obtained from fitting to a quadratic. Statistical errors are obtained from the regression analysis, and are assigned completely to the

Intercomparison of stratospheric ozone and temperature measurements

G. O. Braathen et al.

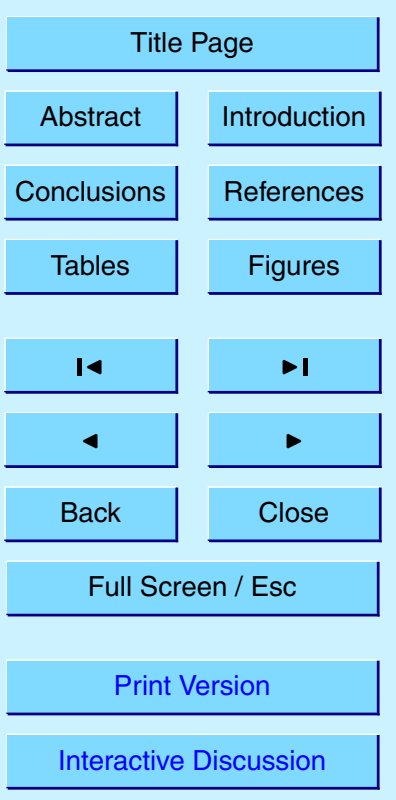

(c) EGU 2004 
error in ozone concentration. The elastic channels provide ozone measurements up to $50 \mathrm{~km}$, and during periods of high loadings of volcanic aerosols, the Raman channels can be used to extract ozone (McGee, 1993). More detail about the retrieval of ozone concentrations from the GSFC lidar data can be obtained from (McGee et al., 1995).

Temperature is retrieved from the elastic and Raman backscatter from the reference wavelength. The method is essentially that described by (Hauchecorne and Chanin, 1980). The Goddard retrieval is initialized at high altitude with temperature, using an atmospheric model. Once the data is initialized, temperature can be retrieved from the lidar derived relative density profile, using the ideal gas equation and assuming that 10 the atmosphere is in hydrostatic equilibrium. The Raman scattered data at $382 \mathrm{~nm}$ is used to retrieve temperature below about $28 \mathrm{~km}$. This works well during periods when there is little "contamination" from volcanic aerosols (Gross et al., 1997).

\subsection{CNRS ozone lidar}

Systematic stratospheric ozone lidar measurements began in 1986 at OHP (Godin et 15 al., 1989). Since then, various improvements were brought to the experimental system with the implementation of a mechanical chopper and the change of the laser sources in 1991. The absorbed radiation is emitted by a XeCl excimer laser at $307.9 \mathrm{~nm}$ and the reference line is provided by the third harmonic of a Nd:YAG laser at $355 \mathrm{~nm}$. Both lasers operate at a repetition rate of $50 \mathrm{~Hz}$. In the beginning of 1994, the ozone lidar receiving system was completely modified with the implementation of new optical and electronic detecting systems in order to improve the temporal resolution of the measurement and the accuracy in the presence of volcanic aerosol (Godin-Beekmann et al., 2003). With this new configuration, 3 ozone profiles are obtained simultaneously: two so-called "Rayleigh" profiles corresponding to the atmospheric elastic scattering and one so-called "Raman" profile due to the first Stokes vibrational Raman scattering of the emitted wavelengths by molecular nitrogen. The Rayleigh signals provide an ozone profile from $18 \mathrm{~km}$ to $50 \mathrm{~km}$, while the Raman signals are used to test the linearity of the Rayleigh signals in the low stratosphere and to provide an ozone pro-

ACPD

$4,5303-5344,2004$

Intercomparison of stratospheric ozone and temperature measurements

G. O. Braathen et al.

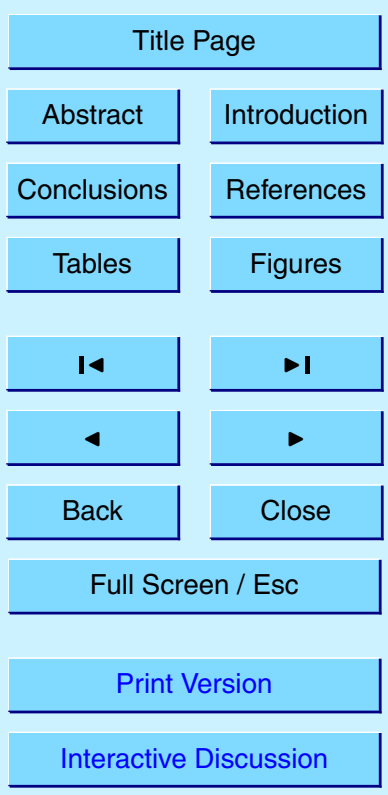

(C) EGU 2004 
file unperturbed by the aerosol, from the tropopause to $25 \mathrm{~km}$. The final ozone profile is computed from the combination of the Raman and the Rayleigh profiles. The altitude range where the Raman and the Rayleigh profiles are combined depends on the aerosol content in the lower stratosphere.

5 2.2.1. Algorithm

First, in order to increase the signal-to-noise ratio, the lidar signals are time averaged over the whole measurements period ( 3 to $4 \mathrm{~h}$ in general). Several corrections are then applied to the averaged signal, such as (i) the background correction where the background light is estimated using a linear regression in the altitude range where the lidar 10 signal is negligible $(80-150 \mathrm{~km})$, and (ii) the dead time correction effect since photon counting is used for the acquisition of the signals. The ozone number density is retrieved from the derivation of lidar signals. In addition to differentiation, it is necessary in the DIAL technique to use a low-pass filter in order to account for the rapid decrease of the signal-to-noise ratio in the high altitude range. In our case, the logarithm of each signal is fitted to a 2 nd order polynomial and the ozone number density is computed from the difference of the derivative of the fitted polynomial. The smoothing is achieved by varying the number of points on which the signals are fitted. The ozone number density is corrected from the Rayleigh extinction using composite pressuretemperature profiles computed from nearby radio soundings performed in Nîmes and the CIRA model. The resolution is calculated from the cutoff frequency of the low-pass filter defined at $-3 \mathrm{~dB}$. The relation between the filter cutoff frequency and the number of points used was obtained empirically by calculating the filter transfer function for various filter orders.

The vertical resolution of the two ozone lidars as a function of altitude is shows in 25 Fig. 1.

ACPD

$4,5303-5344,2004$

Intercomparison of stratospheric ozone and temperature measurements

G. O. Braathen et al.

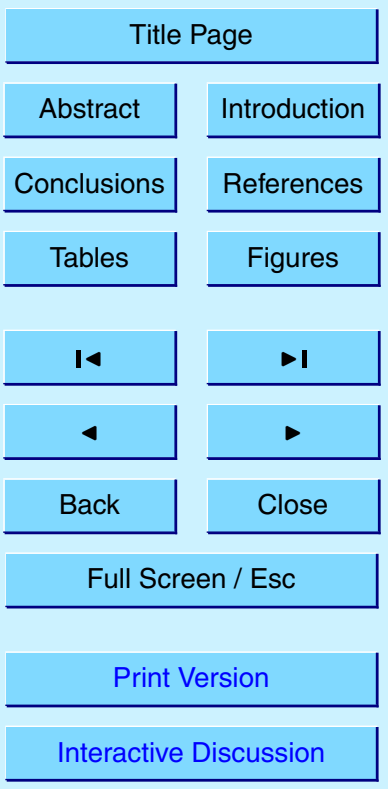


The CNRS Rayleigh lidar system measures specifically stratospheric temperature. This lidar uses the second harmonic of a Nd:Yag pulse Laser $(532.2 \mathrm{~nm})$. The laser 5 provides an energy of $350 \mathrm{~mJ}$ per pulse at $50 \mathrm{~Hz}$. The beam divergence is reduced using an afocal system to $0.04 \mathrm{mrad}$. The receiving area is composed by a mosaic of four $0.5 \mathrm{~m}$ diameter mirrors. Light is collected using optical fibres (diameter: $300 \mu \mathrm{m}$ ) located at each of the four focus points leading to a field of view equal to $0.4 \mathrm{mrad}$. The four fibres are mixed together in a single fibre. As the first channel received too many 10 backscattered photons compared to the bandwidth of the counting system, a second independent channel of lower sensitivity was implemented to cover the lower altitude range $(30-50 \mathrm{~km})$. It is composed of a $0.2 \mathrm{~m}$ diameter mirror providing a field of view of $0.55 \mathrm{mrad}$. The two optical fibres drive the photons up to two receiver boxes where filtering is insured using an interference filter of $1 \mathrm{~nm}$.

15 Detection is made by a cooled Hamamatsu photomultiplier tubes running in a counting mode. Counting gating is $0.5 \mu$ s providing a $75 \mathrm{~m}$ vertical resolution. Electronic gates are used on each channel in an effort to reduce the effects of the large initial burst of light and the resulting signal induced noise. Reasons for the choice of this instrumental configuration have been detailed in (Keckhut et al., 1993). In contrast to the 20 GSFC system that provides temperature and ozone profiles simultaneously, the CNRS temperature lidar is a specific instrument independent of the OHP ozone lidar. This system, providing temperature profiles routinely since the 1980's, has already been described and the instrumental choice discussed (Keckhut et al., 1993). The main characteristics of the OHP system were compared to the GSFC system already during 25 the last intercomparison in 1992 (Singh et al., 1996). The main differences between the two lidar systems are the wavelength $(532 \mathrm{~nm})$, the field of view of the receiver (OHP smaller than GSFC), and the way the altitude range is extended by using a second channel with a lower sensitivity. For this last design GSFC makes a second chan-

\section{Intercomparison of stratospheric ozone and temperature measurements}

G. O. Braathen et al.

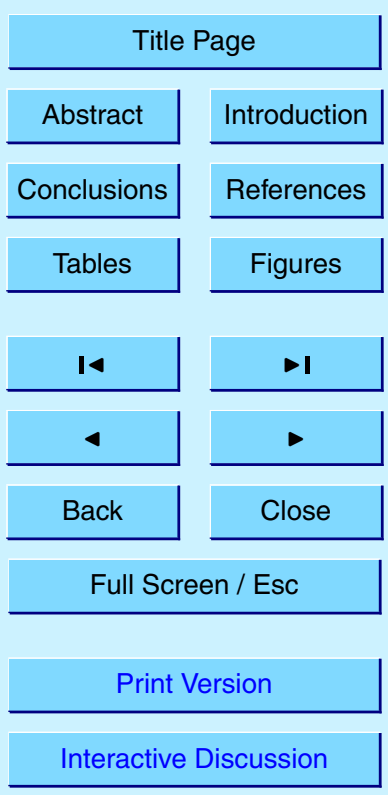

(C) EGU 2004 
nel with a beamsplitter while the CNRS system uses an independent telescope with a larger field of view than the high sensitivity channel. This solution allows to check the alignment between emission and reception and uses the smallest field of view for the high sensitivity channel. Very good agreement was found during the first intercom5 parison campaign in 1992 as no significant difference between the two data set was noted (Singh et al., 1996). The mean difference was smaller than $0.5 \mathrm{~K}$ in the stratosphere and less than $2 \mathrm{~K}$ in the mesosphere. Since the last intercomparison at OHP, several modifications have been implemented. In September 1994, the temperature lidar went through an extensive modification including the optical receiver, the counting 10 system, and software for acquisition and temperature retrievals. The electronics have been changed to provide an adjusted vertical resolution down to $45 \mathrm{~m}$ compared to the $300 \mathrm{~m}$ achieved previously. This vertical resolution improvement was motivated by the observation of some small scale dynamical features, such as those produced by gravity waves and tides.

15 2.3.2. Algorithm

The method used to retrieve temperature profiles from the molecular backscattered signal and the associated errors has been given in detail by (Hauchecorne and Chanin, 1980). The two existing channels have been mixed together to provide a single signal for the entire height range. This is achieved by comparing the two channels in the overlapping altitude range $(30-50 \mathrm{~km})$ and by calculating the ratio between the two channels. Simultaneously, the channel providing the highest sensitivity (upper altitude range) is corrected for non-linearity effects by assuming an exponential function of the number of shots and by considering the channel for low altitudes as a reference. The signal-induced noise (SIN) is considerably reduced using electronic gating, but can still
ACPD

4, 5303-5344, 2004
Intercomparison of stratospheric ozone and temperature measurements

G. O. Braathen et al.

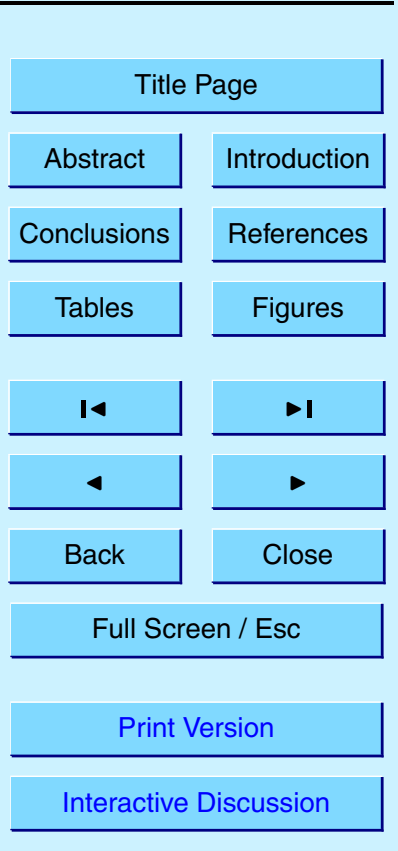

(C) EGU 2004 
where the backscattered signal is small compared to the noise, a quadratic fit of the estimated noise is calculated. This noise function is then extrapolated back to lower altitudes and subtracted from the data.

Computation of temperature profiles requires a pressure initialisation. Instead of 5 assuming that the pressure at the top of the profile is equal to the value given by the standard atmosphere model, the scale height of the pressure (which is directly related to the temperature) is used to adjust the atmospheric model. Part of the actual algorithm can be found in (Keckhut et al., 1993, 2001), and in (Singh et al., 1996). Software codes from both teams have been compared during the last intercomparison 10 (Singh et al., 1996) and this study reveals differences smaller than the noise $(<1.5 \mathrm{~K})$ up to $70 \mathrm{~km}$. Since then, the CNRS temperature software has also been recoded. The physics remain unchanged but many functionalities have been automated. The main improvements of the data processing concerns the selection of the raw data, the calculation of the range and level of the background, the initialisation, the 2 channels adjustments, and the non-linearity correction. This new version has been tested and compared with the Jet Propulsion Laboratory version (Leblanc et al., 1998).

The accuracy in determining the density and temperature is directly related to the photon noise and is associated to the temporal and vertical resolution. The statistical noise increases with altitude and suddenly becomes very large as the signal amplitude reaches the noise level. Relative and absolute uncertainties have been identified and quantified using simulated data (Leblanc et al., 1998). For NDSC purposes the vertical resolution is constant with altitude and equal to around $3 \mathrm{~km}$. The integration time changes from night to night as it depends on the weather conditions. The amplitude of the correction of the non-linearities of the counting is around $1-2 \mathrm{~K}$ and is determined with an accuracy of $0.1 \mathrm{~K}$. The error due to the initialisation was estimated to be equal to $15 \%$ at the initialisation level. The calculation of uncertainty shows that this error becomes rapidly negligible compared to the noise statistics.

Table 1 compares the main characteristics of the three systems.
ACPD

4, 5303-5344, 2004

\section{Intercomparison of stratospheric ozone and temperature measurements}

G. O. Braathen et al.

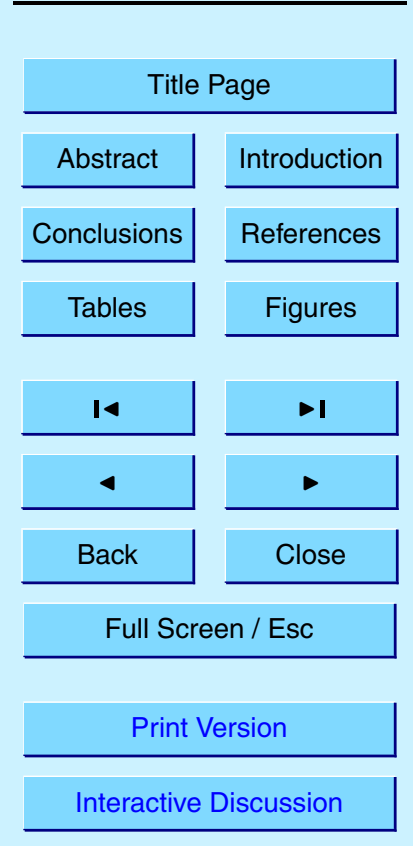

(C) EGU 2004 
The ozonesondes are Z type ECC sondes manufactured by ENSCI. The ozonesonde is tied to a standard meteorological radiosonde (RS80-18H since February 1997). The 5 balloon ( $1200 \mathrm{~g}$, chloroprene latex) is provided by Kaysam. The equipment is tied to the balloon by a $9 \mathrm{~m}$ cord. The sensor current is converted in a numerical value by a T-Max interface board which also manage the meteorological parameters (PTU). The telemetry signal is converted to an RS-232 signal with a modem and fed into a serial port of a PC computer.

\subsubsection{Data processing}

Data processing is performed in two steps. During the first step the data from the telemetry are converted to geophysical data, i.e. pressure, air temperature, relative humidity, box temperature and ozone sensor current. The second step begins by filtering and eliminating erroneous lines. The ozone partial pressure is calculated from the measured ECC current during this step. Corrections due to the background current and pump efficiency at lower pressures are calculated according to the standard guidelines of Ozone sondes users' manual (Vaisala Technical Manual, 1988). The height is calculated using the hydrostatic equation. Corrections for radiation and ventilation are made.

Ozonesondes from OHP were one of the different types tested during the JOSIE intercomparison experiment conducted in February 1996 at the KFA Center, Jülich, Germany). The results show that the OHP ozonesondes exhibit a mean value of the total ozone normalization factor of 1.04 with a standard deviation of 0.04 . These values are close to the values obtained around the year $(1.07 \pm 0.06)$ (Smit et al., 1997).

Intercomparison of stratospheric ozone and temperature measurements

G. O. Braathen et al.

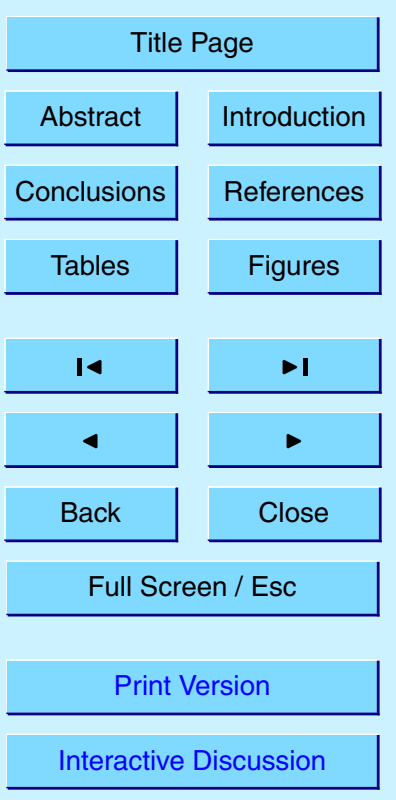

(C) EGU 2004 
The campaign lasted from 1-18 July 1997. Measurements were obtained during 14 nights with the CNRS ozone lidar, during 13 nights with the CNRS temperature lidar and during 15 nights with the GSFC lidar. The two ozone lidars did not operate simulta-

5 neously as they use the same pair of wavelengths. However, as the CNRS temperature lidar operates at $532 \mathrm{~nm}$ compared to $351 \mathrm{~nm}$ for the NASA/GSFC system, operations and processing have been done on exactly the same time periods.

Ozonesondes were launched five times during the campaign. Table 2 shows when the three instruments were active.

The campaign was carried out as a blind intercomparison. Each research group submitted preliminary data within a few hours after the experiment. The data were submitted to the NADIR data base at the Norwegian Institute for Air Research (NILU) via FTP. Each group had separate directories that could be accessed by that group and the referee only. After the completion of the campaign the participants got a deadline of

151 October 1997 for submitting final data. Both preliminary and final data directories and files were only accessible to the data provider and the referee. After 1 October the data could no longer be modified and the directories were opened so that the participants could read the other groups' data.

\section{Results from the ozone lidars}

\subsection{Data comparison}

As seen from Table 2 there were 13 nights where the two ozone lidars measured sequentially. Figure 2 shows a typical coincident ozone profile intercomparison for 8 July 1997, when both ozone lidars were operating. In this plot the error bars are based on the estimated errors in ozone as obtained from the algorithm used to deduce ozone from the raw data. Figure 3 shows a typical coincident profile intercomparison for 1

Intercomparison of stratospheric ozone and temperature measurements

G. O. Braathen et al.

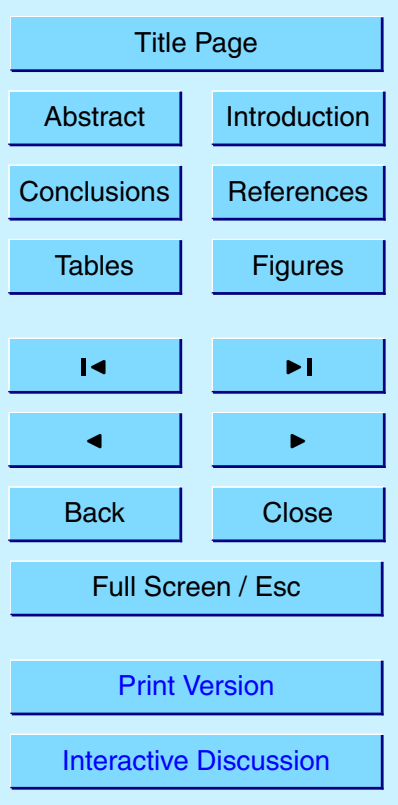

(c) EGU 2004 
July 1997, when the GSFC lidar was operating during an ozonesonde launch. The error bars for the sonde data have been estimated by assuming that the uncertainty in the sonde data is $5 \%$.

Data from the 13 nights when both lidar systems were operating have been combined

5 in order to produce average profiles for the two systems. Figure 4 shows the two average ozone profiles obtained by CNRS and GSFC, respectively. The thickness of the curves represents the standard deviations of the average curves. The equation used to calculate the standard deviations is given below in the section on error analysis (Eq. 1). The difference between the two average profiles is within $5 \%$ in the $17-42 \mathrm{~km}$ 10 height range. It is seen from the figure that the two average profiles coincide quite well over most of the height range from 12-50 km. However, in the region from about 20 to about $29 \mathrm{~km}$ the difference between the two average profiles is larger than what can be explained from the statistical errors alone. As an independent test the five ozonesonde profiles have been averaged and compared to an averaged GSFC lidar profile based on the same five nights, i.e. 1, 5, 9, 11 and 18 July. The result of this comparison is shown in Fig. 5. In this plot the thickness of the curves represents the standard deviations of the averages. It is seen that the agreement between the two profiles is quite good (well within 5\%) over the height range from 19 to $31 \mathrm{~km}$ and that there is no statistically significant difference (to the $2 \sigma$ level) between the two profiles over this height range.

20 The relatively large difference between the two profiles at $18.5 \mathrm{~km}$ is caused by the fact that the ozonesondes have a better vertical resolution and better resolve narrow features, such as laminae, in the ozone profile. This is similar to that observed in the intercomparison between the two ozone lidars. A second test would be to compare the ozonesondes with the CNRS ozone lidar. Unfortunately there are only three coincident measurements, on 5, 11 and 18 July, respectively. Data from these three nights have been averaged and the result is shown in Fig. 6 . Although there is more noise in these data it looks as if there is no significant difference between the lidar and the sonde data over most of the 19-31 km region.

It can be seen from the comparison of the ozonesondes and the ozone lidar that the

\section{Intercomparison of stratospheric ozone and temperature measurements}

G. O. Braathen et al.

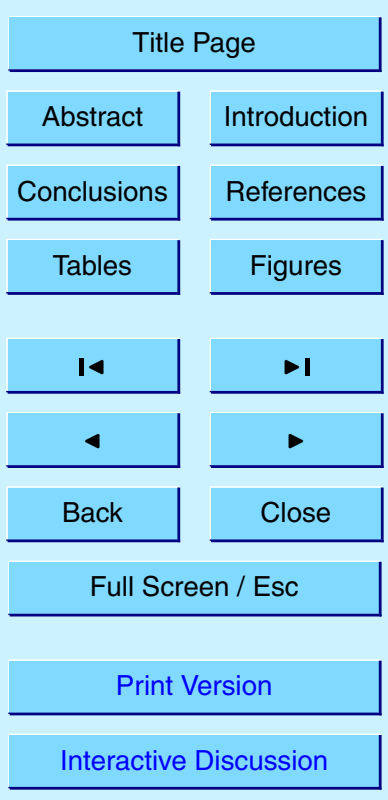

(C) EGU 2004 
upper part of the profile exhibits a noticeably smaller standard deviation for the lidar data than for the sonde data. It is well known that the precision of the ECC sonde drops at higher altitudes, so this observation is in line with what one would expect. Lower down (from 10-17 km) the sondes and lidars show comparable standard deviations.

5 The large standard deviations seen here reflect the large atmospheric variability in this altitude region.

\subsection{Ozone comparison with common temperature profiles}

For the retrieval of ozone profiles from the raw data the GFSC group use temperature data obtained with the same system. The CNRS ozone lidar group use temperature 10 profiles from the CNRS temperature lidar for archiving in the NDSC data archive. For a first evaluation temperature data from the National Meteorological Center (NMC) in the US are used. This difference can of course lead to differences in the ozone profile that are neither ascribable to the lidar system itself nor the algorithms used to retrieve the ozone profile.

15 In order to make an objective comparison of the two ozone lidar systems it was decided that both groups should use a common set of temperature profiles for the data reduction. The GSFC group provided the campaign participants with temperature profiles from the NMC. A separate set of ozone profiles were calculated based on these temperature data. Figure 7 shows a sample pair of profiles from 8 July. Data 20 from the 13 nights when both lidar systems were operating have been combined in order to produce average profiles for the two systems. Figure 8 shows the two ozone average profiles obtained by CNRS and GSFC, respectively. The difference between the two average profiles is also shown. Comparing the difference curve in Fig. 8 with the corresponding curve in Fig. 4 shows that the two curves are quite similar. The 25 largest difference between the two figures is in the lower part (below $16 \mathrm{~km}$ ) of the profile. Here the comparison between the two ozone lidars is better when the two systems use the same temperature data. However, the improvement is not enough to explain the significant difference between the two systems in the $20-29 \mathrm{~km}$ height
ACPD

$4,5303-5344,2004$

Intercomparison of stratospheric ozone and temperature measurements

G. O. Braathen et al.

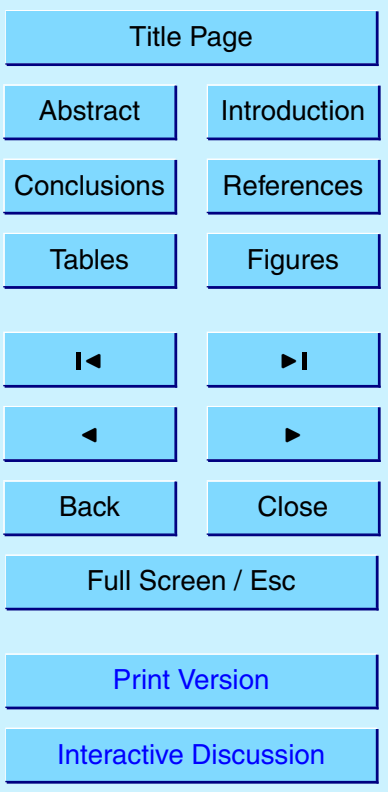

(C) EGU 2004 
range. This shows that the differences between the CNRS mean profile and the GSFC mean profile are not caused by the fact that the two groups use different temperature

\subsection{Error analysis}

5 In the figures above that show pair-wise comparisons of single profiles the uncertainties are calculated from the photon counting statistics of the measurement. The figures that show average profiles display uncertainties that are calculated from the standard deviation of the mean (Eq. 1 below). It will be of interest to verify that the error estimates calculated from the photon counting statistics are realistic. This can be done by calculating the standard deviation of the mean. This approach is not valid for the lower part of the stratosphere where the natural day to day variability is quite large. Above approx. $20 \mathrm{~km}$ the ozone concentration does not vary much from one day to the next, so standard deviations of the mean above this altitude can be used as a realistic test of the instrumental error estimates. The relative standard deviation of the mean is defined as:

$\sigma_{r}=\frac{\sqrt{\frac{\sum\left(y_{i}-\bar{y}\right)^{2}}{N(N-1)}}}{\bar{y}}$,

where $y_{i}$ is the ozone value of the individual measurement and $\bar{y}$ is the mean value. The relative error based on the instrumental error estimates is defined as:

$$
\sigma_{l}=\frac{\frac{\sum\left(\sigma_{i}\right)}{N}}{\bar{y}},
$$

where $\sigma_{i}$ is the calculated statistical error for each measurement at that altitude level.

Figure 9 shows the relative standard deviation of the mean of the 13 CNRS ozone lidar profiles for the 10-50 km altitude range together with the standard error based on the error estimates from the photon statistics. Figure 10 shows the same for the GSGC

\section{Intercomparison of stratospheric ozone and temperature measurements}

G. O. Braathen et al.

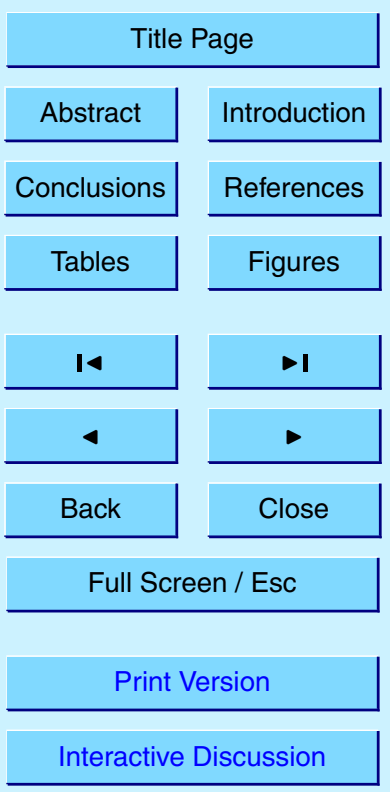

(C) EGU 2004 
lidar. It is seen from these two figures that the uncertainties based on the instrumental errors give a fairly realistic estimate of the real error above $20 \mathrm{~km}$. However, in both figures it can be seen that the instrumental error gives a small under-estimation of the real error. The results from the comparison with the ozonesondes show that the much

5 larger standard deviation below $20 \mathrm{~km}$ cannot be ascribed to the estimated instrumental error alone.

The relative standard deviation of the difference of the means as a function of altitude (given in the right hand panel of Figs. 4, 5, 6 and 8) is calculated using the following equation:

${ }_{10} \sigma_{d}=\sqrt{\left(\frac{\sigma_{1}}{y_{1}}\right)^{2}+\left(\frac{\sigma_{2}}{y_{2}}\right)^{2}} \cdot \frac{y_{2}}{y_{1}} \cdot 100$

where $\sigma_{1}$ and $\sigma_{2}$ are the standard deviations of the two mean profiles and $y_{1}$ and $y_{2}$ are the ozone values of the two mean profiles at any given altitude.

\section{Results from the temperature lidars}

\subsection{Data comparison}

15 As seen from Table 2 there were 13 nights when the two temperature lidars were measuring simultaneously. The temperature comparison error analysis has been treated with the same formalism as the ozone comparison described in the previous section.

The GSFC and the CNRS temperature lidars operate at different wavelengths, which means that they can measure at the same time. Figure 11 shows a sample pair of

coincident profiles from 7 July. Data from the 13 nights when both lidar systems were operating have been combined in order to produce average profiles for the two systems. Figure 12 shows the two average temperature profiles obtained by CNRS and GSFC, respectively. The difference between the two data sets varies between 1.5 and $-1.5 \%$, depending on the altitude. A closer look at Fig. 12 reveals that the two curves look

Intercomparison of stratospheric ozone and temperature measurements

G. O. Braathen et al.

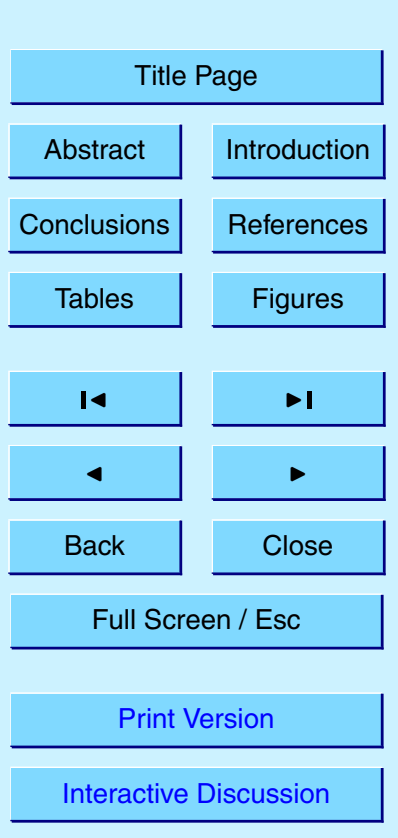

(C) EGU 2004 
like they have been shifted vertically with respect to each other. Plotting each of the profile pairs shows that for certain days the CNRS profile is contained within the GSFC profile, such as in Fig. 11. On other dates the two profiles look vertically shifted, as shown in Fig. 13. Since several profile pairs behave like the example in Fig. 13 the 5 resulting average profiles also look shifted with respect to each other.

On seven occasions the temperature profiles either overlap quite well or are of the type seen in Fig. 11. Averaging these seven profiles from each group leads to the average profiles seen in Fig. 14.

\subsection{Error analysis}

10 In the figures above that show pair-wise comparisons of single profiles the uncertainties are, just as in the ozone case, calculated from the photon counting statistics of the measurement. The figures that show average profiles display uncertainties that are calculated from the standard deviation of the mean (Eq. 1 above). It will again be of interest to verify that the error estimates calculated from the photon counting statistics are realistic. This is done by comparing the standard deviation of the mean with the standard deviations based on the instrumental errors. These comparisons are shown in Fig. 15 (GSFC lidar) and in Fig. 16 (CNRS lidar). It can be seen from these figures that the standard deviation calculated from the instrumental error represents an underestimation of the real standard deviation. This is particularly the case for the GSFC lidar.

\section{Discussion and conclusions}

\subsection{Ozone}

The two ozone lidars agree very well in the $30-40 \mathrm{~km}$ range where the difference between the average profiles is within $2 \%$. This is within the error bars of the two lidars.

\section{Intercomparison of stratospheric ozone and temperature measurements}

G. O. Braathen et al.

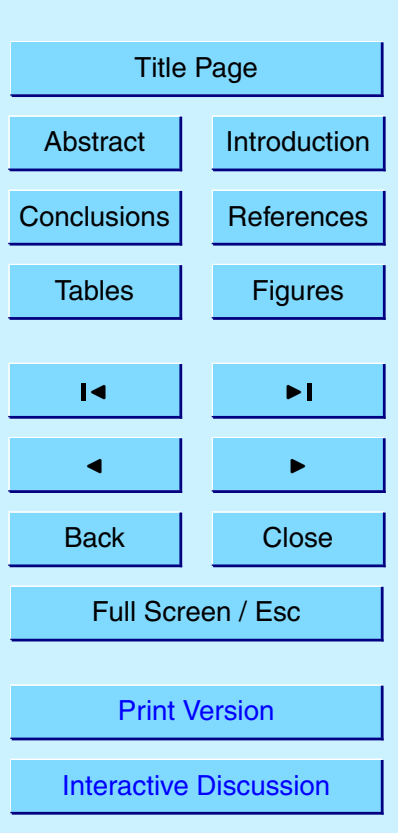

(C) EGU 2004 
In the 20 to $30 \mathrm{~km}$ range there is a discrepancy of approx. 5\% between the two average profiles, and this is larger than can be accounted for by the standard deviations of the mean profiles. The right hand panel of Fig. 4 shows that the difference of the means is significantly different from zero at the $2 \sigma$ level. Below $20 \mathrm{~km}$ the difference 5 varies between $\pm 7 \%$, but this can be explained by the larger short-term variability in this height range together with the fact that the two instruments could not measure at exactly the same time and the fact that the CNRS measurements last twice as long as the GSFC ones. The different vertical resolution (see Fig. 1) of the two lidars in this height range might also explain part of the difference. The good agreement be10 tween the two systems between 30 and $40 \mathrm{~km}$ indicates that there is no height shift between the two systems. Above $40 \mathrm{~km}$ the difference between the two average profiles increases rapidly, but is still within the error bars. Comparison with ozonesondes gives a better agreement for the CNRS lidar in the 20-30 km range, but the number of coincident soundings is quite limited ( 3 and 5 for the two lidar systems, respectively), Al is difficult to draw a definite conclusion on this.

Also, if we look closely at Figs. 4 and 8 , one can see that the difference of the means is somewhat smaller in Fig. 8 than in Fig. 4, in particular around 26-35 km. Between 15 and $25 \mathrm{~km}$ the two error curves are quite similar, but it is interesting to note that below $15 \mathrm{~km}$, there are quite large differences between the difference curves in Figs. 4 and

better when two lidar systems use the same temperature profiles for the data reduction.

\subsection{Temperature}

The difference curve for the two average profiles (Fig. 12, right panel) has a distinct slope. This may indicate a problem with the determination of the height scale for one of the lidars. The type of alternating error up to $1 \%$ might suggest a problem of altitude reference of a few hundred metres (Leblanc et al., 1998). However, such an altitude drift is more difficult to identify in the ozone comparison as $100 \mathrm{~m}$ will have induced less than a $1 \%$ ozone difference, which is smaller than the variability of the difference of the

\section{Intercomparison of stratospheric ozone and temperature measurements}

G. O. Braathen et al.

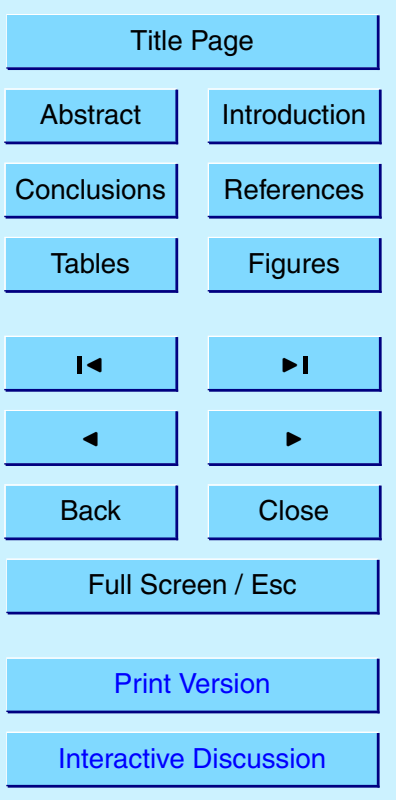

(C) EGU 2004 
means. The fact that other vertical shapes have been observed in the temperature comparison suggest that an altitude drift is not the only source of the discrepancies and further investigation is needed to reduce all the sources of biases less than $1 \%$ in the two systems.

5 In the mesosphere the temperature retrieval is very sensitive to the initialisation procedure and the sky background extraction because the signal is decreasing exponentially with the altitude as well as the signal-induce noise. The altitude range where signal or noise dominate is difficult to determine and depend on the signal/noise ratio that can change considerably from one day to another. The systematic bias that seems 10 to be observed in Fig. 12 may be associated with such problems with one of the lidars. Further investigations are required to improve the retrieval in this range. However, for the NDSC the upper stratosphere is not the first priority.

The last intercomparison revealed a bias of $1 \%$, which is of the same order as the one obtained here. An altitude shift was already independently observed in the OHP 15 temperature series in investigating the continuity of the data. A temperature shift associated with the lidar improvements implemented in September 1994 was observed. The amplitude of the change as a function of altitude was quantified by analysing the full data series with a multi-function regression analysis including a step function to simulate a possible instrumental change as done with rocket analysis (Keckhut et al., 1998). The vertical profile of the bias is very similar to the one observed during the intercomparison, showing a maximum at $40 \mathrm{~km}$ and a secondary maximum of opposite sign at $65 \mathrm{~km}$. The temperature bias is not directly related to an altitude shift as the altitude is related to the temperature gradient but also to the solid angle increasing the effect in the stratosphere compared to the mesosphere. The picture is complicated, though, by the fact that on certain days there is less evidence of a height shift, such as exemplified in Fig. 10. The interpretation of this effect may be found in an additional bias caused by the initialisation process. The last comparison exercise in 1992 included a comparison of the two analysis software codes using the same raw data (Singh et al., 1996). The largest differences was observed in the mesosphere and

\section{Intercomparison of stratospheric ozone and temperature measurements}

G. O. Braathen et al.

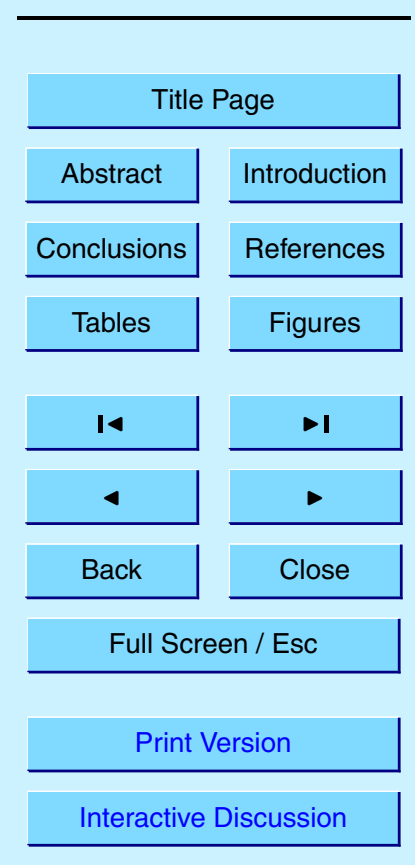

(c) EGU 2004 
was suspected to be due to the initialisation effects as some differences exist between the two algorithms. This effect may be enlarged due to the fact that the signal sets from both instruments do not exhibit the same noise level nor signal level. A bias due to the initialisation depends strongly on the differences between the true mesospheric 5 temperature profile and the atmospheric model used. It may lead to a quite large variability of the amplitude of this bias from successive mean profiles due to the change of mesospheric temperature profiles. Nonetheless the difference between the two average profiles is within $\pm 1.5 \%$ over the entire $28-72 \mathrm{~km}$ height range. Our interpretation of the temperature comparison seems to confirm the presence of a bias in the temper10 ature OHP lidar. The source of this bias is clearly related to an altitude reference shift which has not yet been completely identified, and which is likely to be caused by an electronic delay or by a code acquisition problem. An additional non-systematic bias related to the initialisation may exist some time in one of the two systems and is superimposed on the systematic altitude bias. Some work on this part of the temperature retrieval analysis needs to be carried out in the future to better understand the differences in the mesosphere. An NDSC temperature software comparison is planned for coming years and will include this issue. However, one has to note that mesospheric differences observed during this comparison campaign as well as the last one, are not significant.

20 The conclusion is that mobile systems are quite useful to validate the methodology and measurements up to $1 \%$ but it is probably the limit of the horizontal homogeneity we can get with a lidar network. Then, to achieve a better absolute precision, comparisons with alternative techniques have to be found. To ensure the temporal continuity over decades and check the consistency and the effects of instrumental changes comparisons on a longer term basis are required such as the one performed with the lidar operated simultaneously at Bordeaux (550 km away) during 8 years (Keckhut et al., 2001).
ACPD

4, 5303-5344, 2004

\section{Intercomparison of stratospheric ozone and temperature measurements}

G. O. Braathen et al.

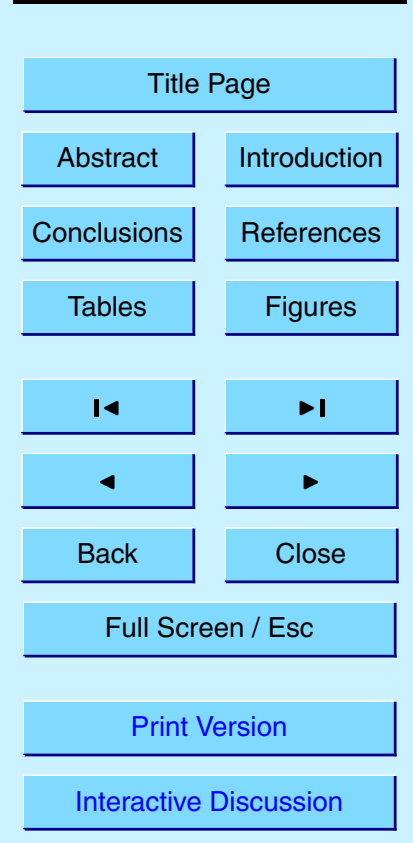

(C) EGU 2004 


\section{References}

Ferrare, R. A., McGee, T. J., Whiteman, D., Burris, J., Owens, M., Butler, J., Barnes, R. A., Schmidlin, F., Komhyr, W., Wang, P. H., McCormick, P. H., and Miller, A. J.: Lidar measurements of stratospheric temperature during STOIC, J. Geophys. Res., 100, 9303-9312, 1995.

Godin-Beekmann, S., Porteneuve, J., and Garnier, A.: Systematic DIAL ozone measurements at Observatoire de Haute-Provence, J. Env. Monitoring, 5, 57-67, 2003.

Gross, M. R., McGee, T. J., Ferrare, R. A., Singh, U., and Kimvilikani, P.: Temperature Measurements Made with a Combined Rayleigh-Mie/Raman Lidar, Applied Optics, 24, 5987-5995, $10 \quad 1997$.

Guirlet, M., Keckhut, P., Godin, S., and Mégie, G.: Description of the long-term ozone data series obtained from different instrumental techniques at a single location: the Observatoire de Haute-Provence (43.9 $\left.\mathrm{N}, 5.7^{\circ} \mathrm{E}\right)$, Ann. Geophys., 18, 1325-1339, 2000.

Hansen, G., Svenøe, T., Chipperfield, M. P., Dahlback, A., and Hoppe, U. P.: Evidence of 15 substantial ozone depletion in winter 1995/96 over Northern Norway, Geophys. Res. Lett., 24, 799-802, 1997.

Hauchecorne, A. and Chanin, M. L.: Density and temperature profiles obtained by lidar between 30 and $70 \mathrm{~km}$, Geophys. Res. Lett., 7, 564-568, 1980.

Hauchecorne, A., Chanin, M. L., and Keckhut, P.: Climatology and trends of the middle atmospheric temperature $(33-87 \mathrm{~km})$ as seen by Rayleigh lidar over the south of france, J. Geophys. Res., 96, 15297-15309, 1991.

Keckhut, P., Hauchecorne, A., and Chanin, M. L.: A critical review of the data base acquired for the long term surveillance of the middle atmosphere by French Rayleigh lidars, J. Atmos. Oceanic Technol., 10, 850-10,867, 1993.

25 Keckhut, P., Hauchecorne, A., and Chanin, M. L.: Mid-latitude long-term variability of the middle atmosphere trends, and cyclic and episodic changes, J. Geophys. Res., 100, 18887-18897, 1995.

Keckhut, P., Schmidlin, F. J., Hauchecorne, A., and Chanin, M. L.: Trend estimates from US rocketsondes at low latitude stations $\left(8^{\circ} \mathrm{S}-34^{\circ} \mathrm{N}\right)$, taking into account instrumental changes and natural variability, J. Atmos. Sol. Terr. Phys., 61, 447-459, 1999.

Keckhut, P., Wild, J., Gelman, M., Miller, A. J., and Hauchecorne, A.: Upper stratosphere using lidar data and NCEP analyses, J. Geophys. Res., 106, 7937-7944, 2001.
ACPD

4, 5303-5344, 2004

Intercomparison of

stratospheric ozone

and temperature

measurements

G. O. Braathen et al.

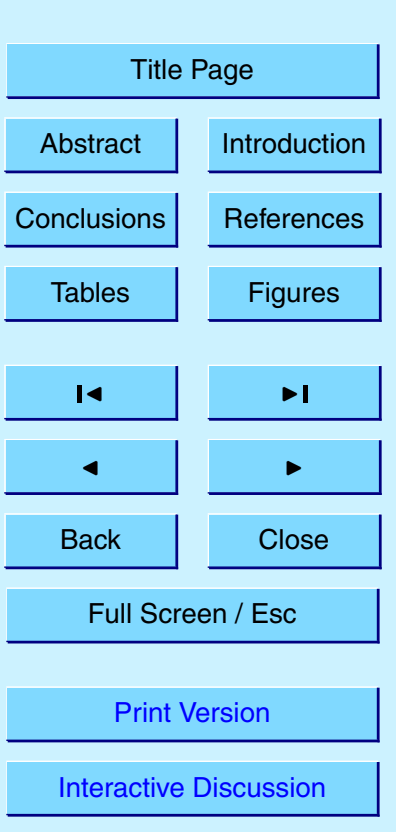

(C) EGU 2004 
Keckhut, P., Hauchecorne, A., Collado, E., Garnier, A., Riedinger, E., and Singh, U.: Averaging methodology of raw lidar signal used for direct detection, Notes des Activités Instrumentales de l'Institut Pierre Simon Laplace, no. 19, 15, 2002.

Komhyr, W. D., Connor, B. J., McDermid, I. S., McGee, T. J., Parrish, A. D., and Margitan, J. J.: 5 Comparison of STOIC 1989 ground-based lidar, microwave spectrometer, and Dobson spectrophotometer Umkehr ozone profiles with ozone profiles from balloon-borne electrochemical concentration cell ozonesondes, J. Geophys. Res., 100, 9273-9282, 1995.

Kurylo, M. J. and Solomon, S.: Network for the Detection of Stratospheric Change, NASA Rep., Code EEU, 1990.

10 Leblanc, T., McDermid, I. S., Hauchecorne, A., and Keckhut, P.: Evaluation and optimisation of lidar temperature analysis algorithms using simulated data, J. Geophys. Res., 103, 61776187, 1998.

Margitan, J. J., Barnes, R. A., Brothers, G. B., Butler, J., Burris, J., Connor, B. J., Ferrare, R. A., Kerr, J. B., Komhyr, W. D., McCormick, M. P., McDermid, I. S., McElroy, C. T., McGee, T. J., Miller, A. J., Owens, M., Parrish, A. D., Parsons, C. L., Torres, A. L., Tsou, J. J., Walsh, T. D., and Whiteman, D.: Stratospheric Ozone Intercomparison Campaign (STOIC) 1989: Overview, J. Geophys. Res., 100, 9193-9207, 1995.

McDermid, I. S., Godin, S., and Walsh, T. D.: Results from the Jet Propulsion Laboratory stratospheric ozone lidar during STOIC 1989, J. Geophys. Res., 100, 9263-9272, 1995.

20 McDermid, I. S., Bergwerff, J. B., Bodeker, G., Boyd, I. S., Brinksma, E. J., Connor, B. J., Farmer, R., Gross, M. R., Kimvilakani, P., Matthews, W. A., McGee, T. J., Ormel, F. T., Parrish, A., Singh, U., Swart, D. P. J., Tsou, J. J., Wang, P. H., and Zawodney, J.: OPAL: Network for the Detection of Stratospheric Change Ozone Profiler Assessment at Lauder, New Zealand, I. Blind Intercomparison, J. Geophys. Res., 103, 28 683-28 692, 1998.

McGee, T. J., Whiteman, D., Ferrare, R., Butler, J. J., and Burris, J. F.: STROZ LITE: Stratospheric ozone lidar experiment, Opt. Eng., 30, 31-39, 1991.

McGee, T. J., Gross, M. R., Ferrare, R., Heaps, W., and Singh, U. N.: Raman DIAL measurements of stratospheric ozone in the presence of volcanic aerosols, Geophys. Res. Lett., 20, 955-958, 1993.

30 McGee, T., Newman, P., Gross, M., Singh, U., Godin, S., Lacoste, S., and Mégie, G.: Correlation of ozone loss with the presence of volcanic aerosols, Geophys. Res. Lett., 21, $2801-$ 2801, 1994.

McGee, T. J., Ferrare, R. A., Whiteman, D. N., Butler, J. J., Burris, J. F., and Owens, M. A.:

ACPD

4, 5303-5344, 2004

Intercomparison of

stratospheric ozone

and temperature measurements

G. O. Braathen et al.

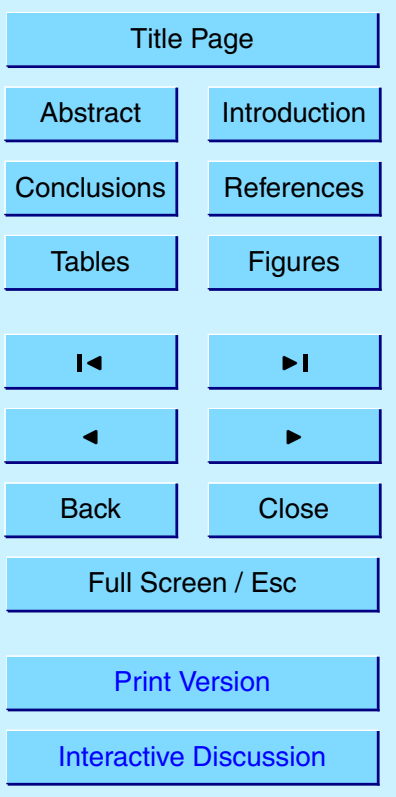

(C) EGU 2004 
Lidar measurements of stratospheric ozone during the STOIC campaign, J. Geophys. Res., 100, 9255-9262, 1995a.

McGee, T. J., Gross, M. T., Singh, U. N., Butler, J. J., and Kimvilakani, P. E.: Improved stratospheric ozone lidar, Opt. Eng., 34, 1421-1430, 1995b.

5 McPeters, R. D., Hofmann, D. J., Clark, M., Flynn, L. Froidevaux, L., Gross, M., Johnson, B., Koenig, G., Liu, X., McDermid, S., McGee, T., Murcray, F., Newchurch, M. J., Oltmans, S., Parrish, A., Schnell, R., Singh, U., Tsou, J. J., Walsh, T., and Zawodny, J. M.: Results from the 1995 Stratospheric Ozone Profile Intercomparison at Mauna Loa, J. Geophys, Res., 104, 30 505-30 514, 1999.

10 Rex, M., Harris, N. R. P., von der Gathen, P., Lehmann, R., Braathen, G. O., Reimer, E., Beck, A., Chipperfield, M. P., Alfier, R., Allaart, M., O'Connor, F., Dier, H., Dorokhov, V., Fast, H., Gil, M., Kyrö, E., Litynska, Z., Mikkelsen, I. S., Molyneux, M. G., Nakane, H., Notholt, J., Rummukainen, M., Viatte, P., and Wenger, J.: Prolonged stratospheric ozone loss in the 1995-96 Arctic winter, Nature, 389, 835-838, 1997.

15 Schulz, A., Rex, M., Harris, N. R. P., Braathen, G. O., Reimer, E., Alfier, R., Kilbane-Dawe, I., Eckermann, S., Allaart, M., Alpers, M., Bojkov, B., Cisneros, J., Claude, H., Cuevas, E., Davies, J., De Backer, H., Dier, H., Dorokhov, V., Fast, H., Godin, S., Johnson, B., Kois, B., Kondo, Y., Kosmidis, E., Kyrö, E., Litynska, Z., Mikkelsen, I. S., Molyneux, M. J., Murphy, G., Nagai, T., Nakane, H., O'Connor, F., Parrondo, C., Schmidlin, F. J., Skrivankova, P., Varotsos, C., Vialle, C., Viatte, P., Yushkov, V., Zerefos, C., and von der Gathen, P.: Arctic ozone loss in threshold conditions: Match observations in 1997/1998 and 1998/1999, J. Geophys Res., 106, 7495-7503, 2001.

Shindell D. T., Rind, R., and Lonergan, P.: Increased polar stratospheric ozone losses and delayed eventual recovery owing to increasing greenhouse-gas concentrations, Nature, 392, 589-592, 1998.

Sing, U. N, Keckhut, P., McGee, T. J., Gross, M. R., Hauchecorne, A., Fishbein, E. F., Waters, J. W., Gille, J. C., Roche, A. E. and Russell III, J. M.: Stratospheric temperature measurements by two collocated NDSC lidars during UARS validation campaign, J. Geophys. Res., 101, 10287-10297, 1996.

30 Smit, H. G. J., Sträter, W., Helten, M., Kley, D., Ciupa, D., Claude, H. J., Köhler, U., Hoegger, B., Levrat, G., Johnson, B., Oltmans, S. J., Kerr, J. B., Tarasick, D. W., Davies, J., Shitamichi, M., Srivatsav, S. K., Vialle, C., and Velghe, G.: JOSIE: The 1996 WMO international intercomparison of ozonesondes under quasi flight conditions in the environmental simula-

ACPD

4, 5303-5344, 2004

Intercomparison of

stratospheric ozone and temperature measurements

G. O. Braathen et al.

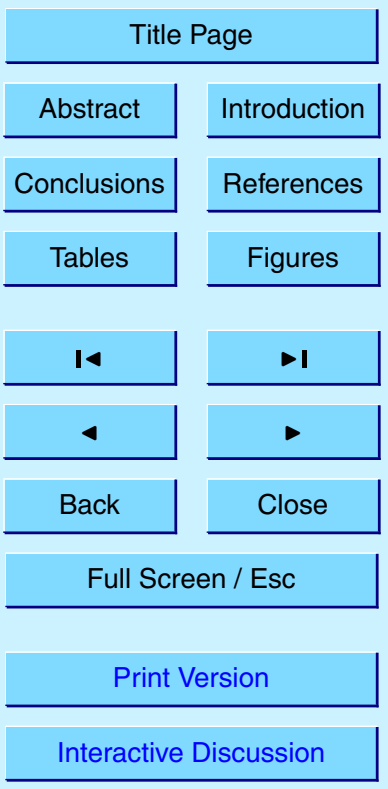

(C) EGU 2004 
tion chamber at Jülich, Proc. XVIII Quadrennial Ozone Symposium and Tropospheric Ozone Workshop, L'Aquila, Italy, edited by Bojkov, R. D. and Visconti, G., 12-21 Sept. 1996.

Steinbrecht, W., Gross, M. R., McGee, T. J., Neuber, R., von der Gathen, P., Wahl, P., Klein, U., and Langer, J.: Results of the $1998 \mathrm{Ny}$-Ålesund Ozone Measurements Intercomparison NAOMI, J. Geophys. Res., 104, 30 515-30 523, 1999.

\section{ACPD}

4, 5303-5344, 2004

\section{Intercomparison of stratospheric ozone and temperature measurements}

G. O. Braathen et al.

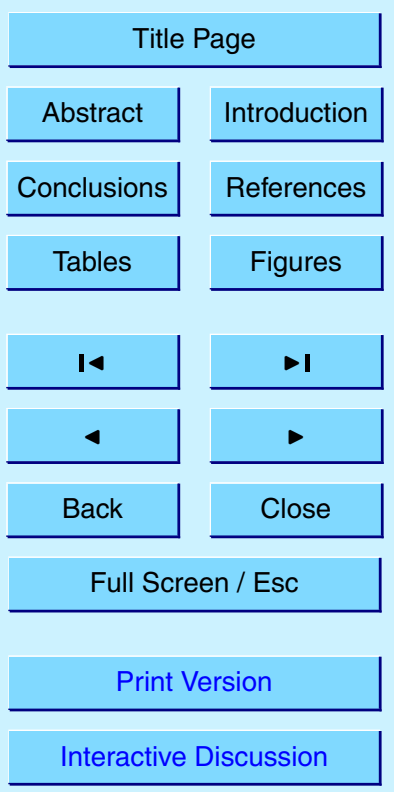

(C) EGU 2004 


\section{ACPD}

Table 1. Lidar characteristics.

4, 5303-5344, 2004

\begin{tabular}{|c|c|c|c|c|c|}
\hline & \multicolumn{2}{|c|}{ CNRS ozone } & \multirow[t]{2}{*}{ CNRS temp. } & \multicolumn{2}{|c|}{ GSFC } \\
\hline & $\lambda_{\text {on }}$ & $\lambda_{\text {off }}$ & & $\lambda_{\text {on }}$ & $\lambda_{\text {off }}$ \\
\hline & \multicolumn{5}{|c|}{ Transmitter } \\
\hline Laser type & $\mathrm{XeCl}$ & Nd:YAG & Nd:YAG & $\mathrm{XeCl}$ & $\mathrm{XeF}$ \\
\hline Transmitted wavelengths, $\mathrm{nm}$ & 308 & 355 & 532 & 308 & 351 \\
\hline Pulse energy, mJ/pulse & 200 & 40 & 350 & 250 & 125 \\
\hline Repetition rate, $\mathrm{Hz}$ & 50 & & 50 & 200 & \\
\hline Pulse width, ns & 10 & & $5-10$ & $\sim 25$ & \\
\hline \multirow[t]{2}{*}{ Emitted beam divergence, mrad } & 0.1 & 0.2 & $4 \times 10^{-2}$ & 0.5 & 1.0 \\
\hline & \multicolumn{5}{|c|}{ Receiver } \\
\hline \multicolumn{6}{|l|}{ Detected wavelengths, $\mathrm{nm}$} \\
\hline elastic return & 308 & 355 & 532 & 308 & 351 \\
\hline Raman return & 332 & 387 & & 332 & 382 \\
\hline \multicolumn{6}{|l|}{ Effective telescope area, $\mathrm{m}^{2}$} \\
\hline high channel & 0.79 & & 0.79 & 0.38 & \\
\hline low channel & 0.79 & & 0.030 .38 & & \\
\hline \multicolumn{6}{|l|}{ Field of view, mrad } \\
\hline high channel & 0.67 & & 0.25 & 2.3 & \\
\hline low channel & 0.67 & & 0.55 & 2.3 & \\
\hline \multicolumn{6}{|l|}{ Emitter-receiver distance, m } \\
\hline high channel & 0.350 & & 0.6 & 2.0 & \\
\hline low channel & 0.350 & & 0.3 & 2.0 & \\
\hline \multirow[t]{2}{*}{ Band-pass filter, nm } & 0.9 & & 1.0 & 2.0 & 5.0 \\
\hline & & & & 6.0 (Raman shifted) & 7.0 (Raman shifted) \\
\hline Ratio upper/lower sensitivity & 10 & & 20 & 24 & \\
\hline $\begin{array}{l}\text { Wavelength-corrected } \\
\text { power aperture, } \mathrm{Wm}^{2}\end{array}$ & 7.9 & 1.58 & $\begin{array}{l}2.7 \text { for high sensitivity } \\
\text { channel, } 0.1 \text { for low } \\
\text { sensitivity channel, both } \\
\text { corrected to } 351 \mathrm{~nm}\end{array}$ & 19 & 9.5 \\
\hline
\end{tabular}

Intercomparison of stratospheric ozone and temperature measurements

G. O. Braathen et al.

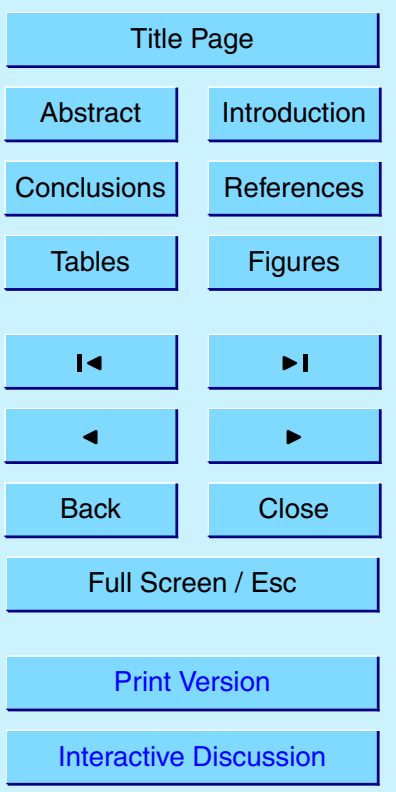




\section{ACPD}

4, 5303-5344, 2004

Table 2. Measurement programme. The numbers give the height range (kma.s.l.) of the measurements.

\begin{tabular}{cccccc}
\hline Date & $\begin{array}{c}\text { CNRS } \\
\mathrm{O}_{3}\end{array}$ & $\begin{array}{c}\text { CNRS } \\
\mathrm{T}\end{array}$ & $\begin{array}{c}\text { GSF } \\
\mathrm{CO}_{3}\end{array}$ & $\begin{array}{c}\text { GSFC } \\
\mathrm{T}\end{array}$ & sondes \\
\hline $97 / 07 / 01$ & & $27-80$ & $10-50$ & $10-79$ & $1-32$ \\
$97 / 07 / 02$ & & & & & \\
$97 / 07 / 03$ & $10-46$ & & $10-51$ & $10-78$ & \\
$97 / 07 / 04$ & & & & & \\
$97 / 07 / 05$ & $10-48$ & $27-81$ & $10-51$ & $10-81$ & $1-33$ \\
$97 / 07 / 06$ & $10-49$ & $27-80$ & $10-53$ & $10-80$ & \\
$97 / 07 / 07$ & $10-48$ & $27-76$ & $10-50$ & $10-79$ & \\
$97 / 07 / 08$ & $10-48$ & $27-75$ & $10-54$ & $10-79$ & \\
$97 / 07 / 09$ & & $27-72$ & $10-54$ & $10-78$ & $1-33$ \\
$97 / 07 / 10$ & $10-46$ & $27-76$ & $10-54$ & $10-76$ & \\
$97 / 07 / 11$ & $10-47$ & $27-77$ & $10-48$ & $10-79$ & $1-33$ \\
$97 / 07 / 12$ & $10-47$ & $27-75$ & $10-53$ & $10-80$ & \\
$97 / 07 / 13$ & $10-47$ & $27-77$ & $10-48$ & $10-77$ & \\
$97 / 07 / 14$ & $10-48$ & $27-74$ & $10-50$ & $10-78$ & \\
$97 / 07 / 15$ & $10-49$ & $27-77$ & $10-52$ & $10-81$ & \\
$97 / 07 / 16$ & $10-47$ & & & & \\
$97 / 07 / 17$ & $10-47$ & & $10-53$ & $10-80$ & \\
$97 / 07 / 18$ & $10-49$ & $27-79$ & $10-52$ & $10-80$ & $1-33$ \\
\hline
\end{tabular}

Intercomparison of stratospheric ozone and temperature measurements

G. O. Braathen et al.

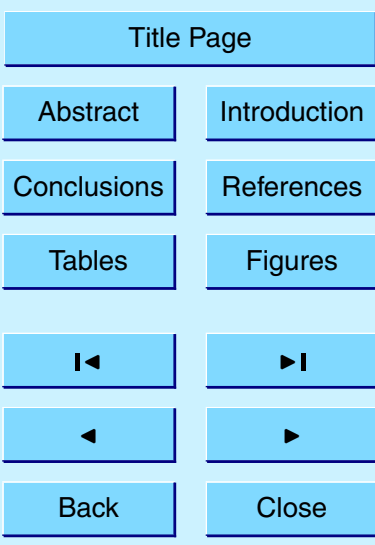

Full Screen / Esc

Print Version

Interactive Discussion

(C) EGU 2004 


\section{ACPD}

4, 5303-5344, 2004

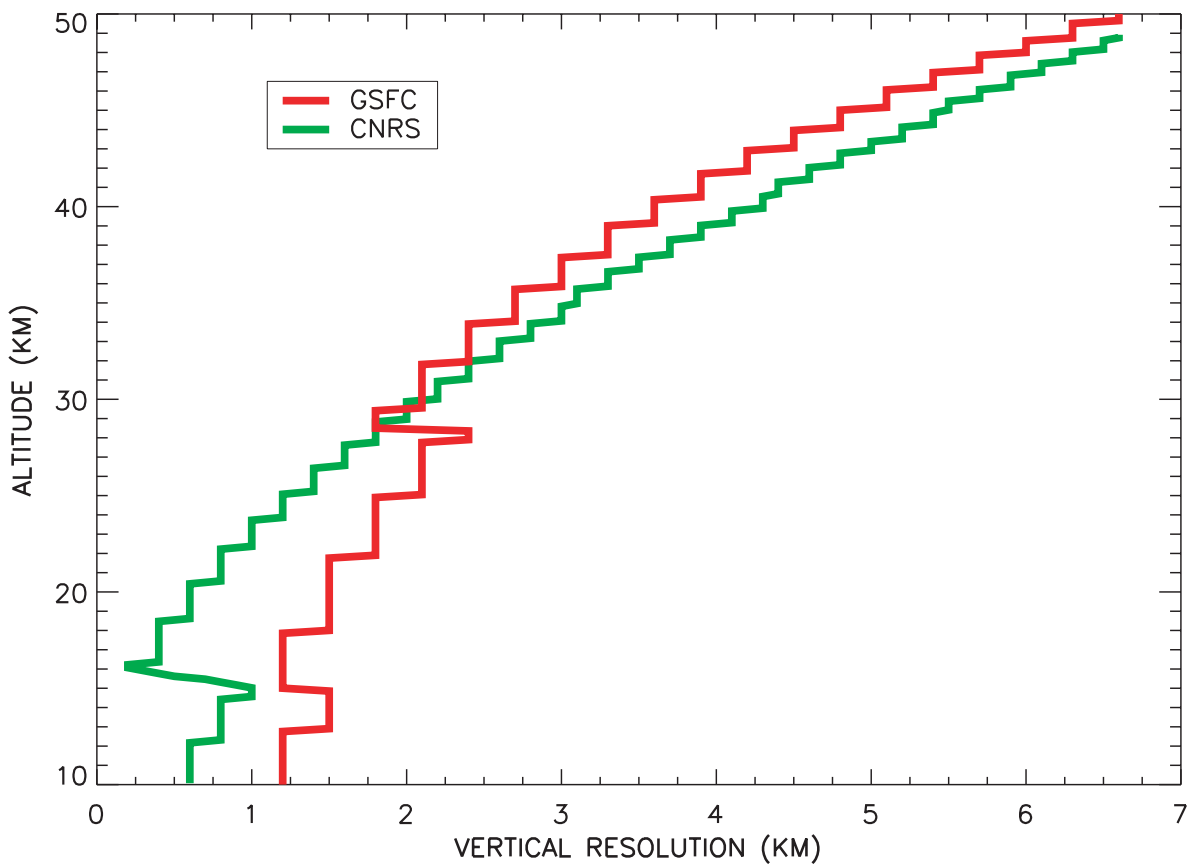

Fig. 1. The vertical resolution of the two ozone lidars as a function of altitude.

\section{Intercomparison of stratospheric ozone and temperature measurements}

G. O. Braathen et al.

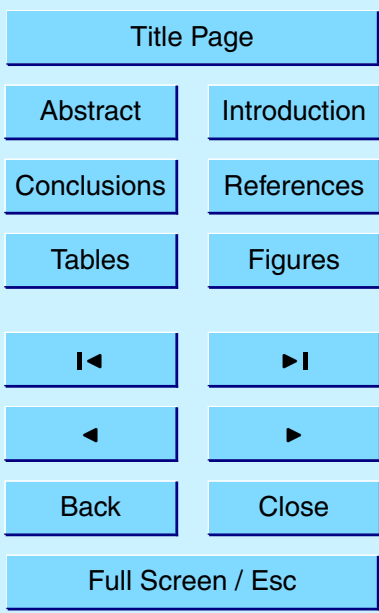

Print Version

Interactive Discussion

(C) EGU 2004 


\section{ACPD}

4, 5303-5344, 2004

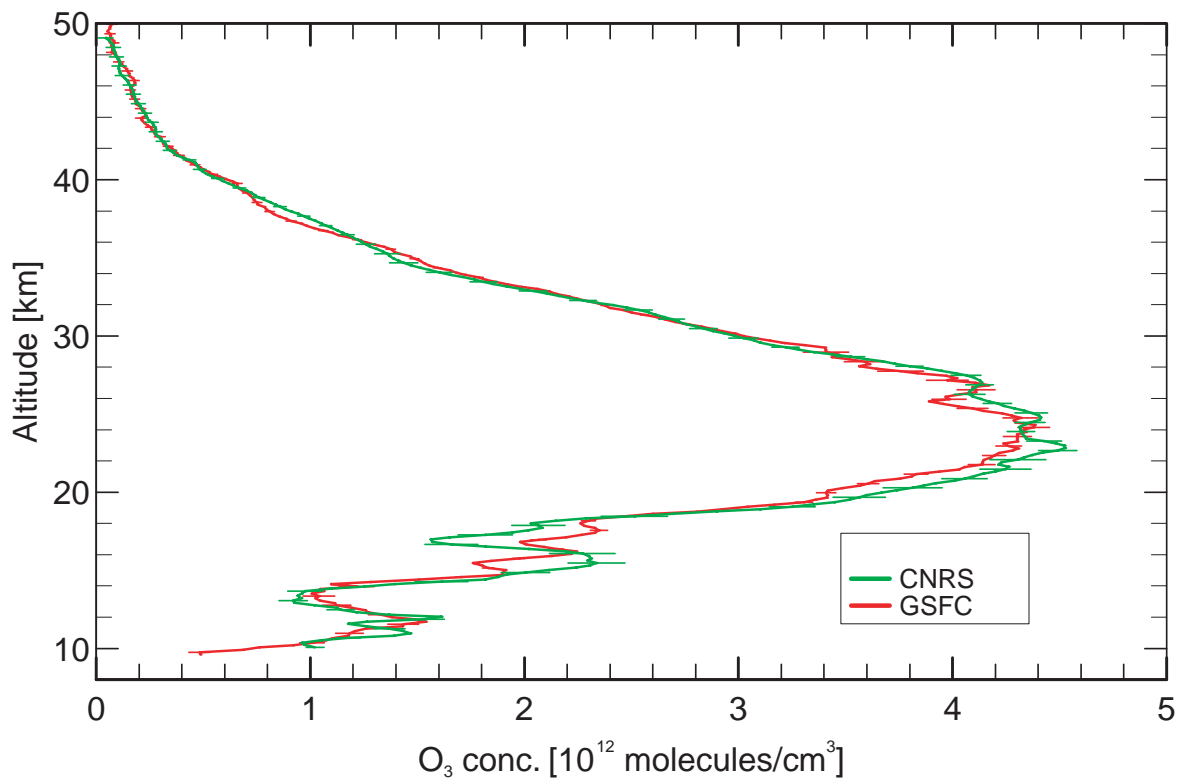

Intercomparison of stratospheric ozone and temperature measurements

G. O. Braathen et al.

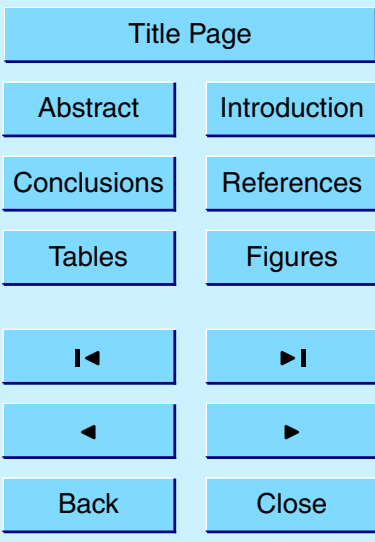

Fig. 2. Comparison of two ozone lidar profiles recorded during the same night (6 July 1997). The green curve represents the CNRS lidar and the red curve represents the GSFC lidar.

Full Screen / Esc

Print Version

Interactive Discussion

(c) EGU 2004 


\section{ACPD}

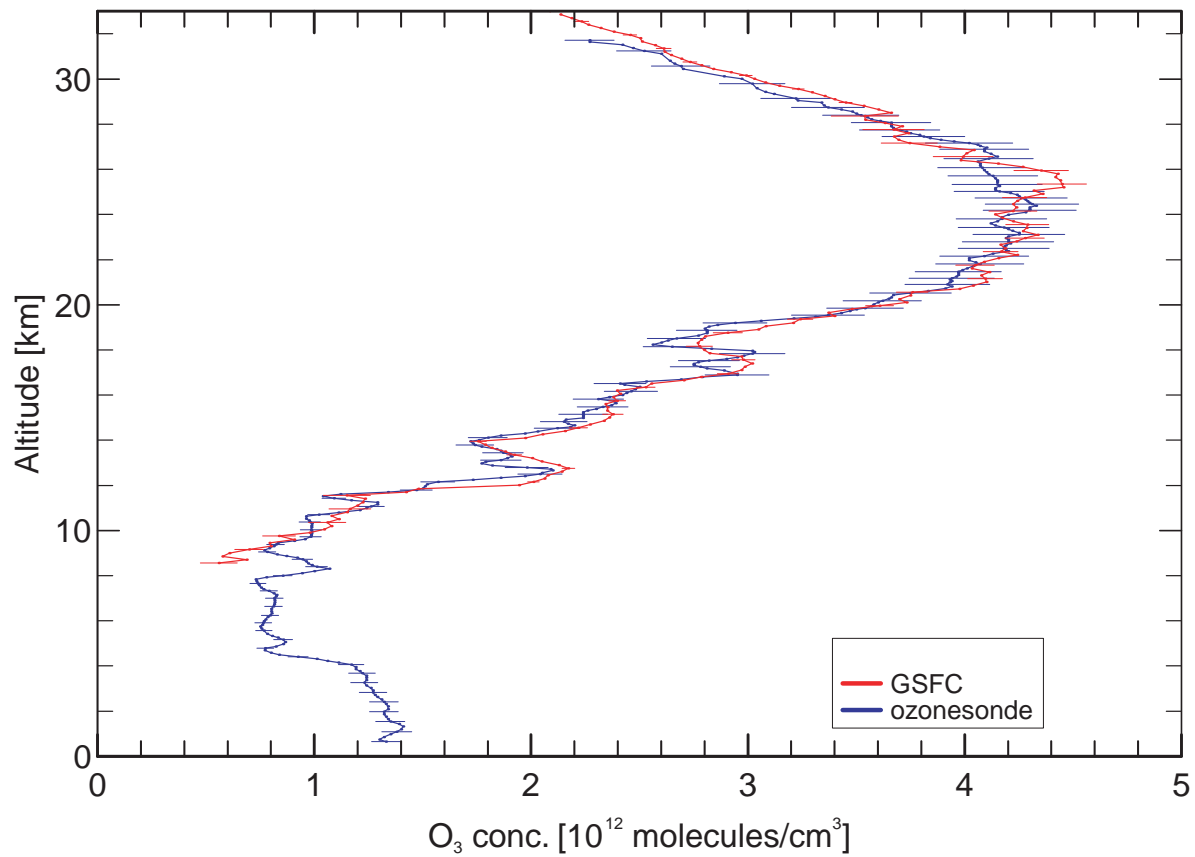

\section{Intercomparison of stratospheric ozone and temperature measurements}

G. O. Braathen et al.

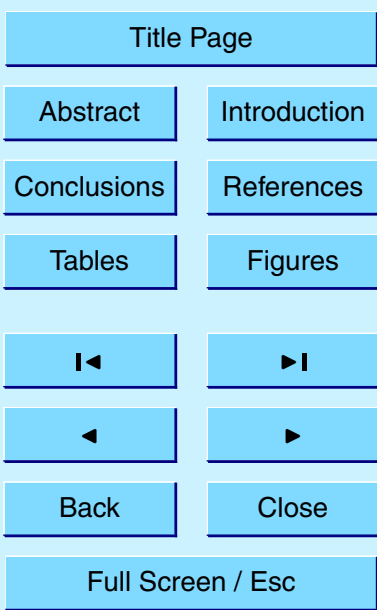

Fig. 3. Comparison of the GSFC lidar and an ozonesonde profile on 1 July 1997.

Print Version

Interactive Discussion

(C) EGU 2004 


\section{ACPD}

4, 5303-5344, 2004
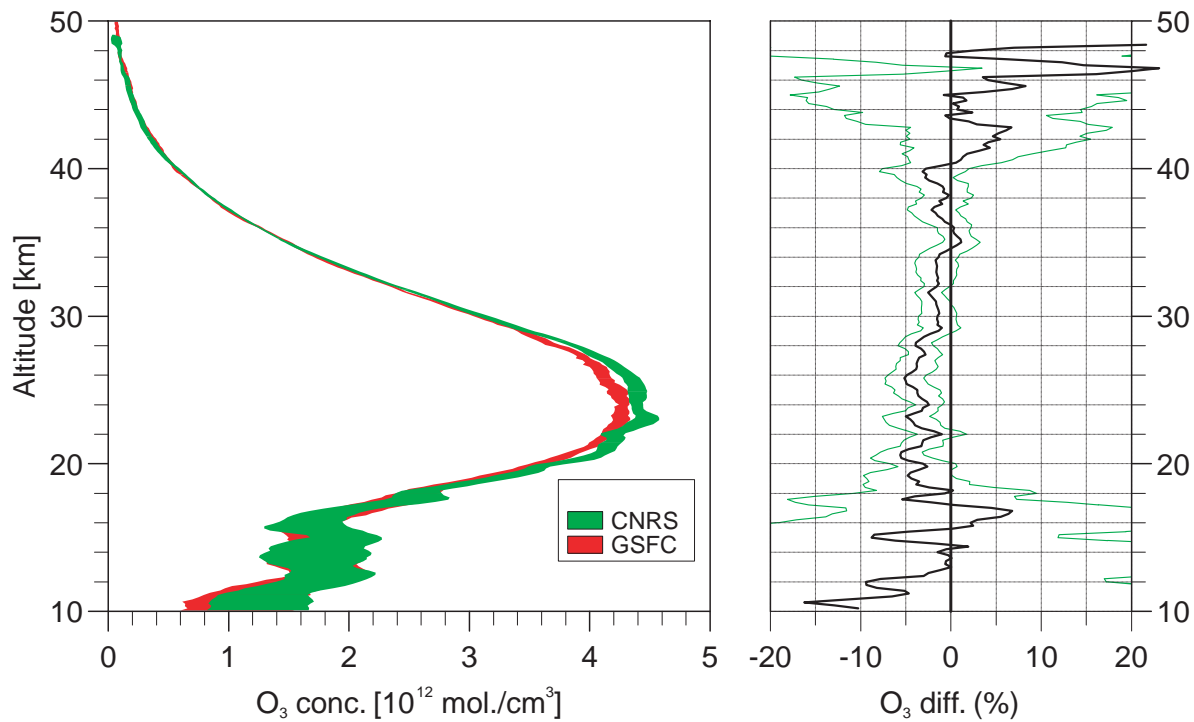

\section{Intercomparison of stratospheric ozone and temperature measurements}

G. O. Braathen et al.

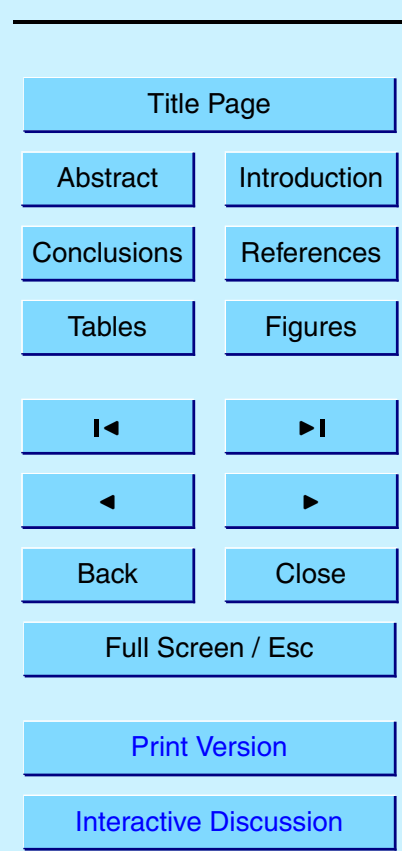

Fig. 4. (Left) Average of 13 coincident ozone profiles from each of the two ozone lidars (red curve, GSFC; green curve, CNRS). The thickness of the red and green curves represents plus/minus two times the standard deviations of the mean of the two data sets. This means that the shading goes from $-2 \sigma$ to $+2 \sigma$. (Right) Percentage ozone concentration difference between the CNRS and the GSFC mean profiles (black curve). The two thin green curves represent the difference of the averages plus/minus two times the relative standard deviation of the difference. See discussion in the main text (section on error analysis) for an exact definition of the standard deviation.

Interactive Discussion 


\section{ACPD}

4, 5303-5344, 2004
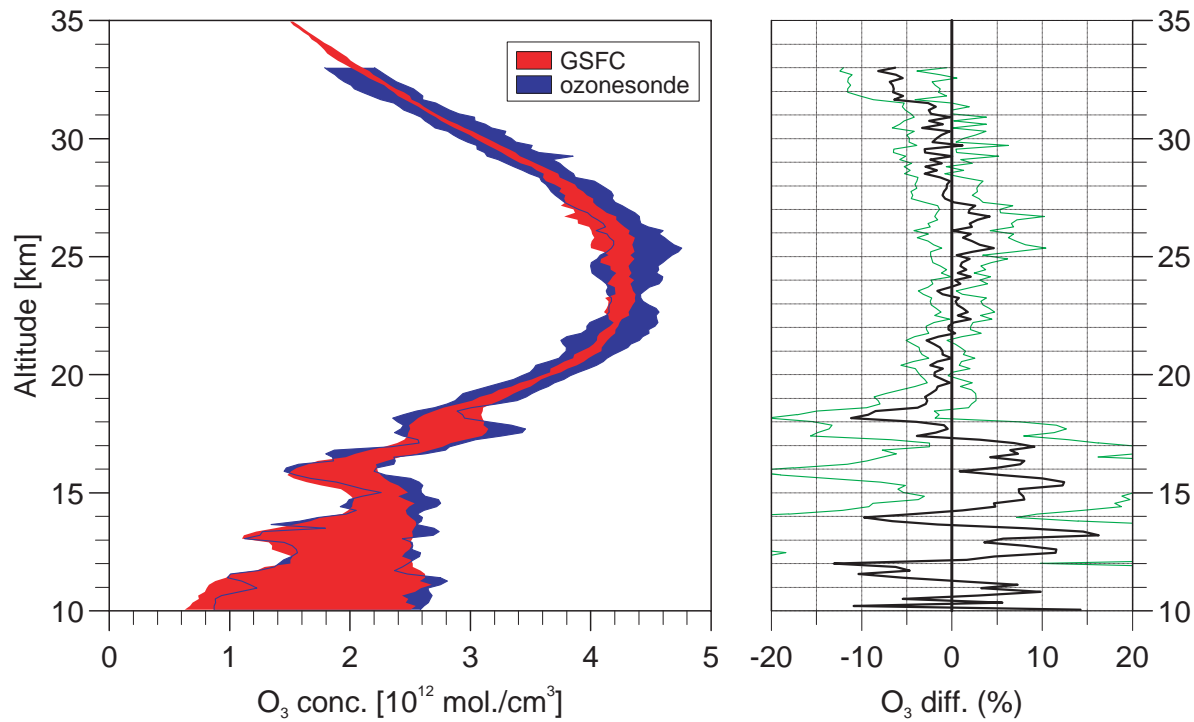

Intercomparison of stratospheric ozone and temperature measurements

G. O. Braathen et al.

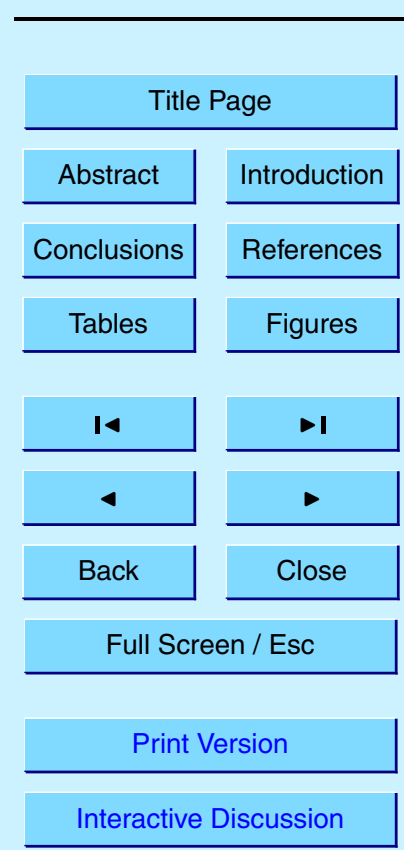

Fig. 5. (Left) Average of 5 coincident ozone profiles from ozonesondes (blue curve) and GSFC lidar (red curve). The thickness of the red and blue curves represent plus/minus two standard deviations for the two data sets. (Right) Percentage ozone concentration difference between the ozonesonde and the GSFC profiles. The green curves on either side represent the difference plus/minus two times the standard deviation of the difference. See the section on error analysis for details on the calculation of standard deviations. 


\section{ACPD}

4, 5303-5344, 2004
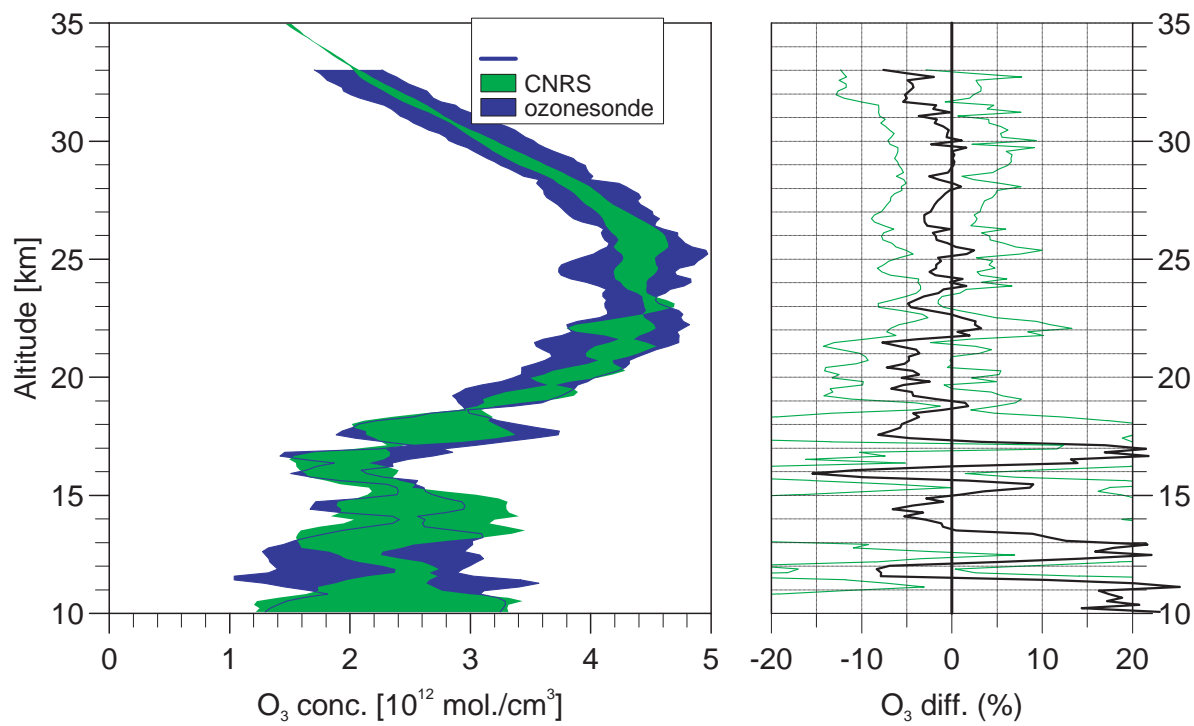

\section{Intercomparison of stratospheric ozone and temperature measurements}

G. O. Braathen et al.

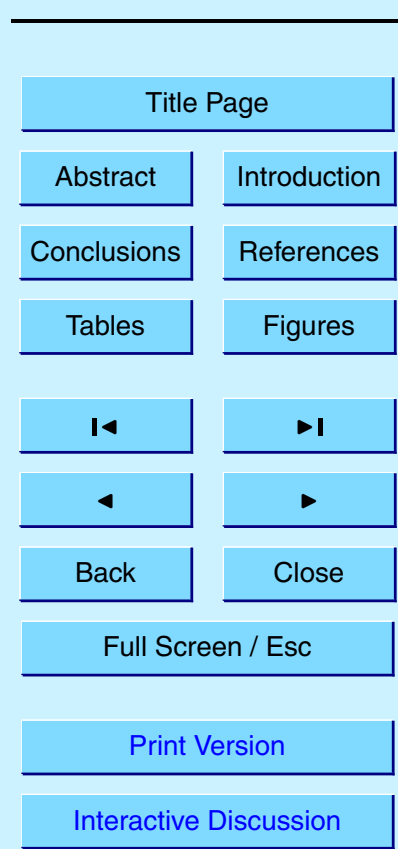

Fig. 6. (Left) Average of 3 coincident ozone profiles from ozonesondes (blue curve) and the CNRS lidar (green curve). The thickness of the green and blue curves represents plus/minus two standard deviations of the two data sets. (Right) Percentage ozone concentration difference between the ozonesonde and the CNRS ozone lidar profiles. The green curves on either side represent the difference plus/minus two times the standard deviation of the difference. See the section on error analysis for details on the calculation of standard deviations.

Interactive Discussion 


\section{ACPD}

4, 5303-5344, 2004

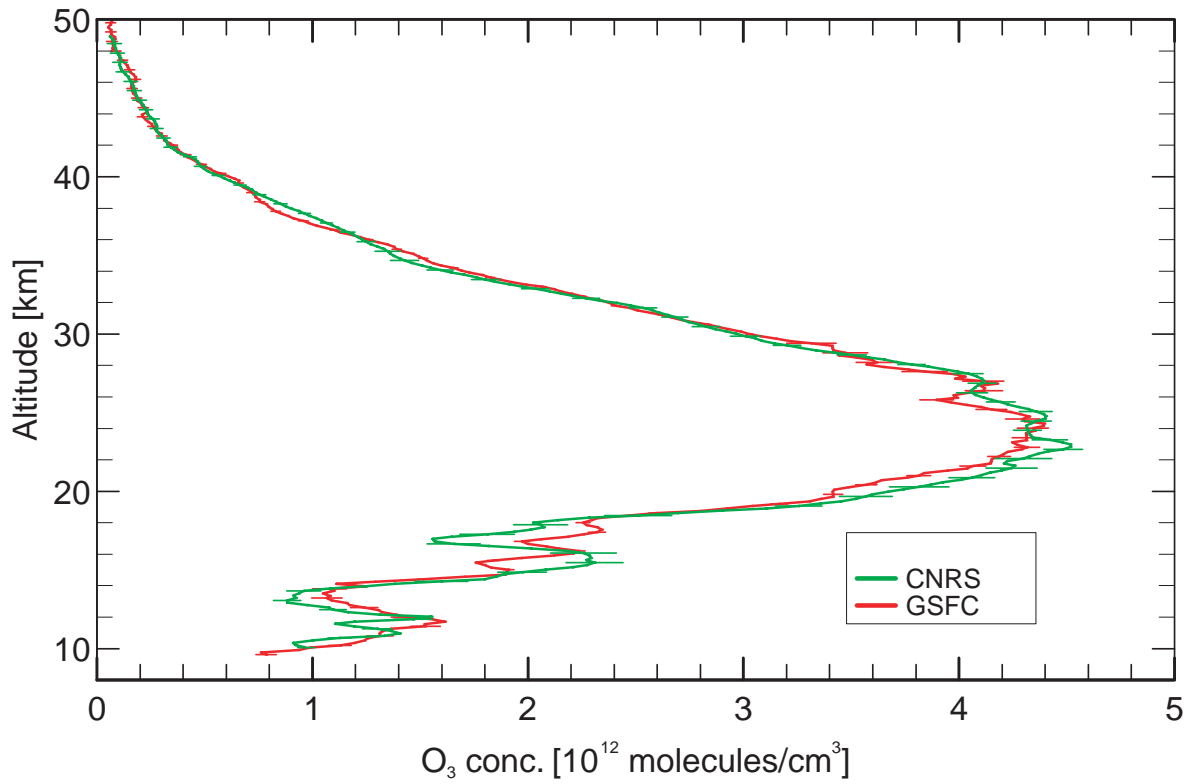

Intercomparison of stratospheric ozone and temperature measurements

G. O. Braathen et al.

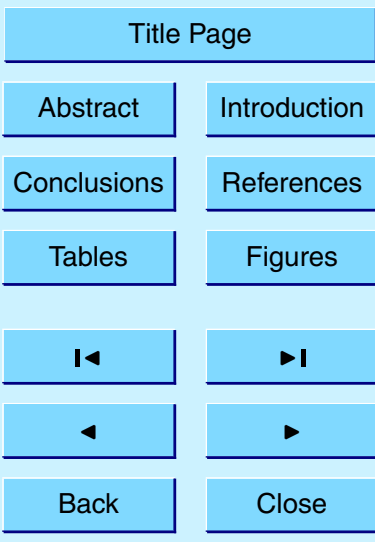

Fig. 7. Comparison of two ozone lidar profiles recorded during the same night (6 July 1997). Green curve is the CNRS lidar and red curve is the GSFC lidar. Both groups have used a common NMC temperature profile for the data retrieval.

Full Screen / Esc

Print Version

Interactive Discussion 


\section{ACPD}

4, 5303-5344, 2004
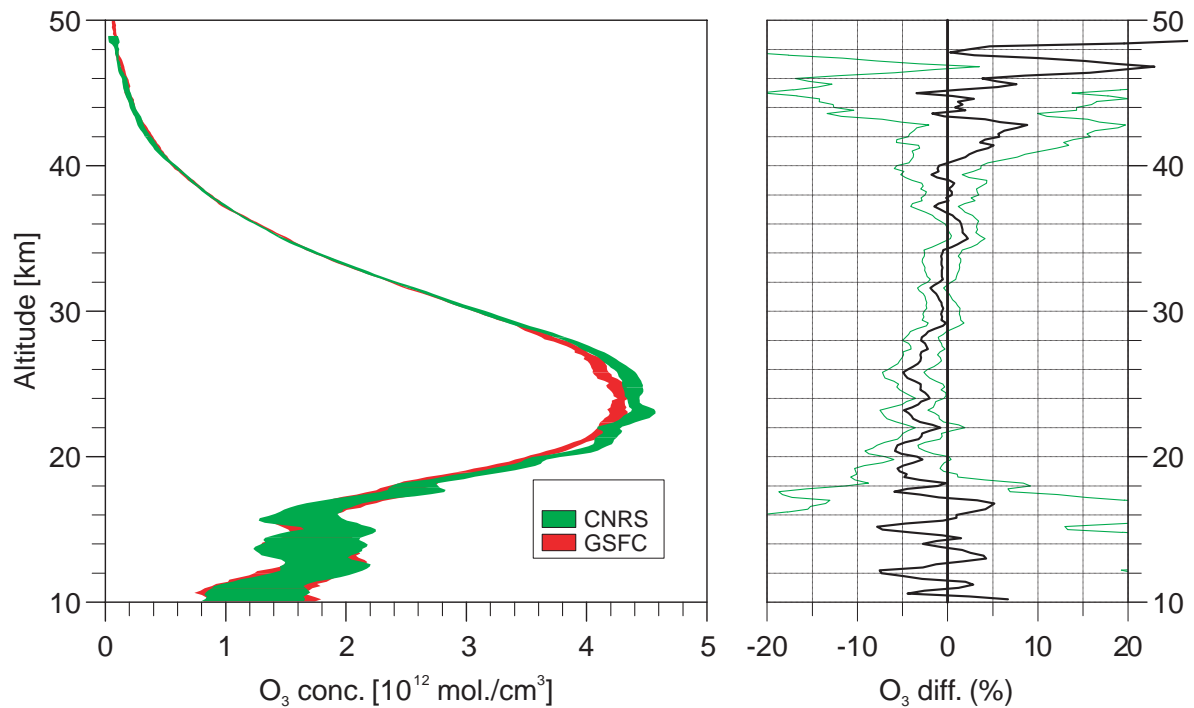

\section{Intercomparison of stratospheric ozone and temperature measurements}

G. O. Braathen et al.

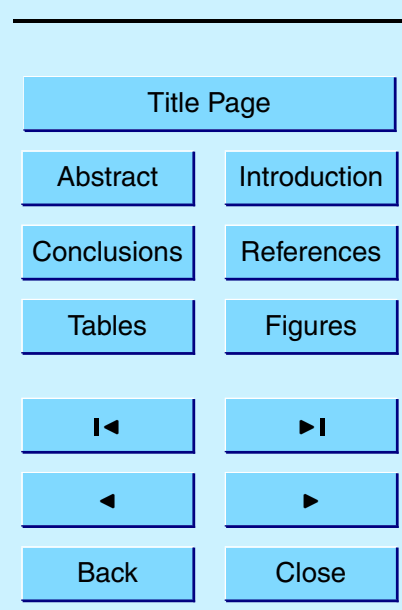

Full Screen / Esc curve) The thin green curves represent two times the standard deviation of the difference. See main text (section on error analysis) for a detailed description of the statistical calculations.

Print Version

Interactive Discussion

(c) EGU 2004 


\section{ACPD}

4, 5303-5344, 2004

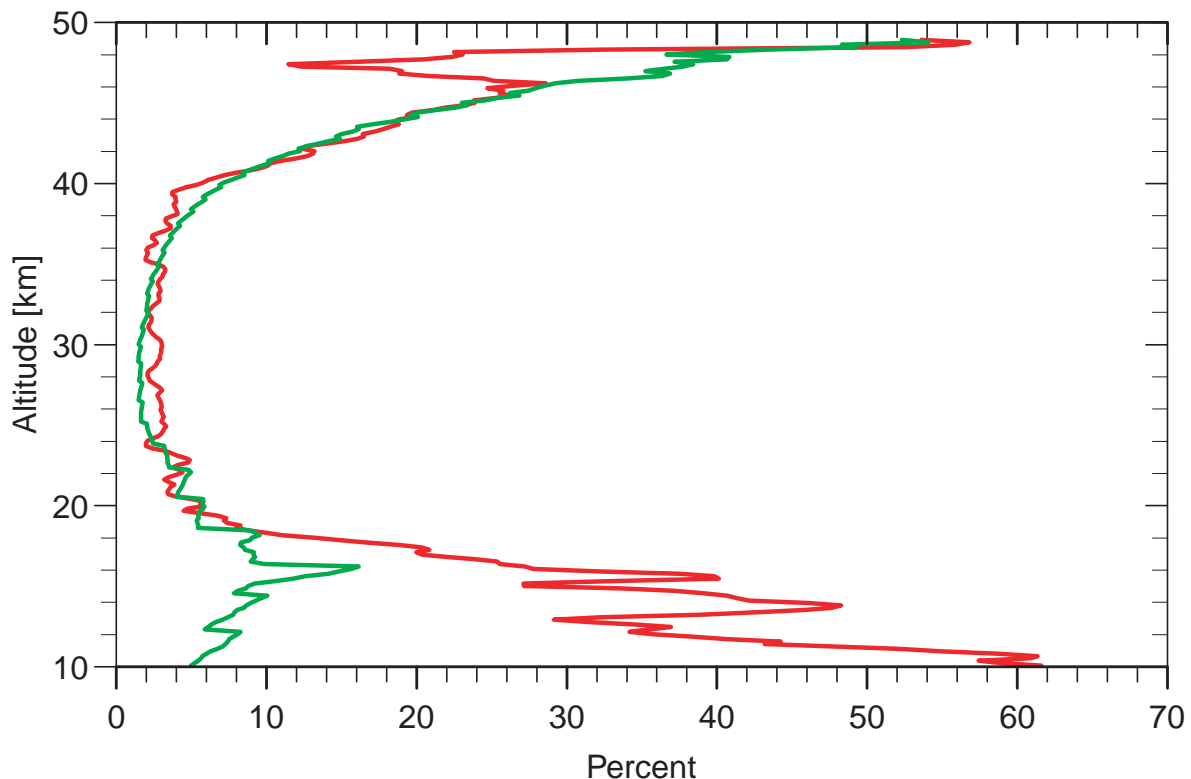

Intercomparison of stratospheric ozone and temperature measurements

G. O. Braathen et al.

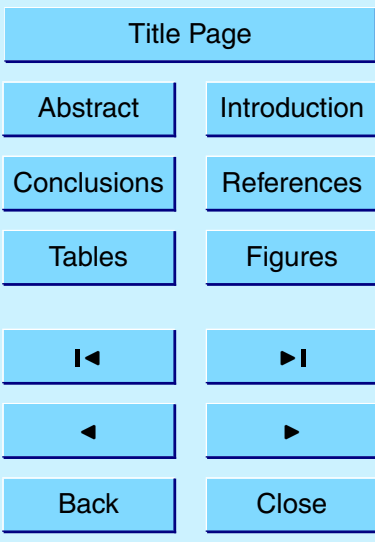

Fig. 9. Relative standard deviation (percent) of the mean of 13 CNRS ozone lidar profiles (red curve) and relative standard deviation (percent) based on the instrumental statistical error (green curve).

Full Screen / Esc

Print Version

Interactive Discussion

(C) EGU 2004 


\section{ACPD}

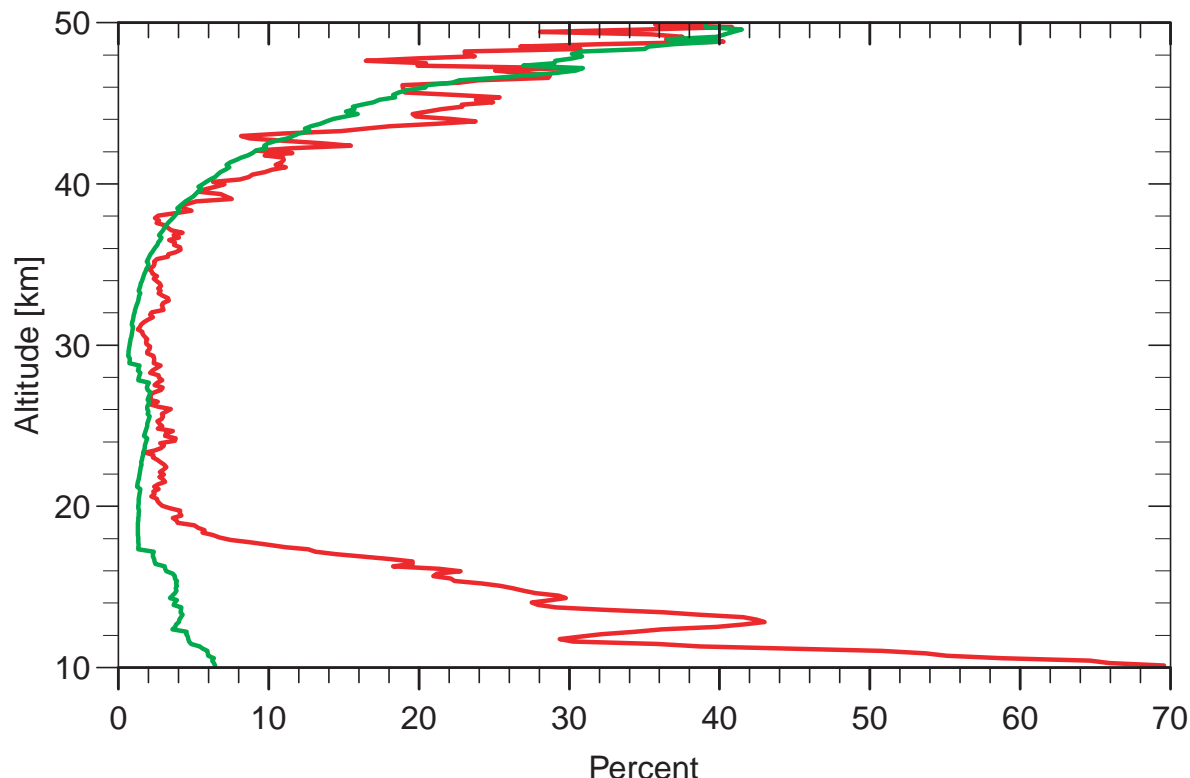

4, 5303-5344, 2004

Intercomparison of stratospheric ozone and temperature measurements

G. O. Braathen et al.

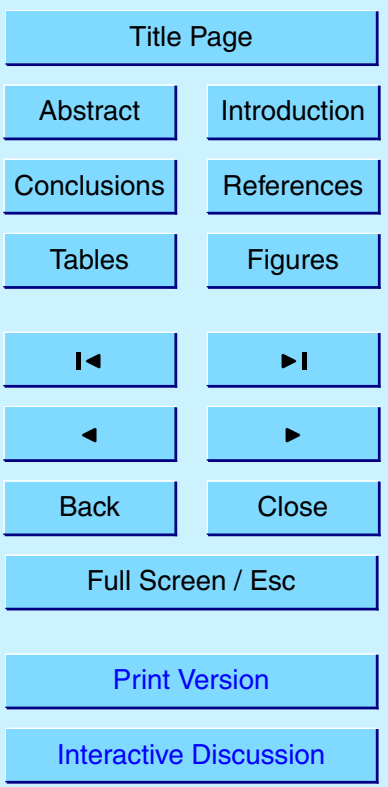




\section{ACPD}

4, 5303-5344, 2004

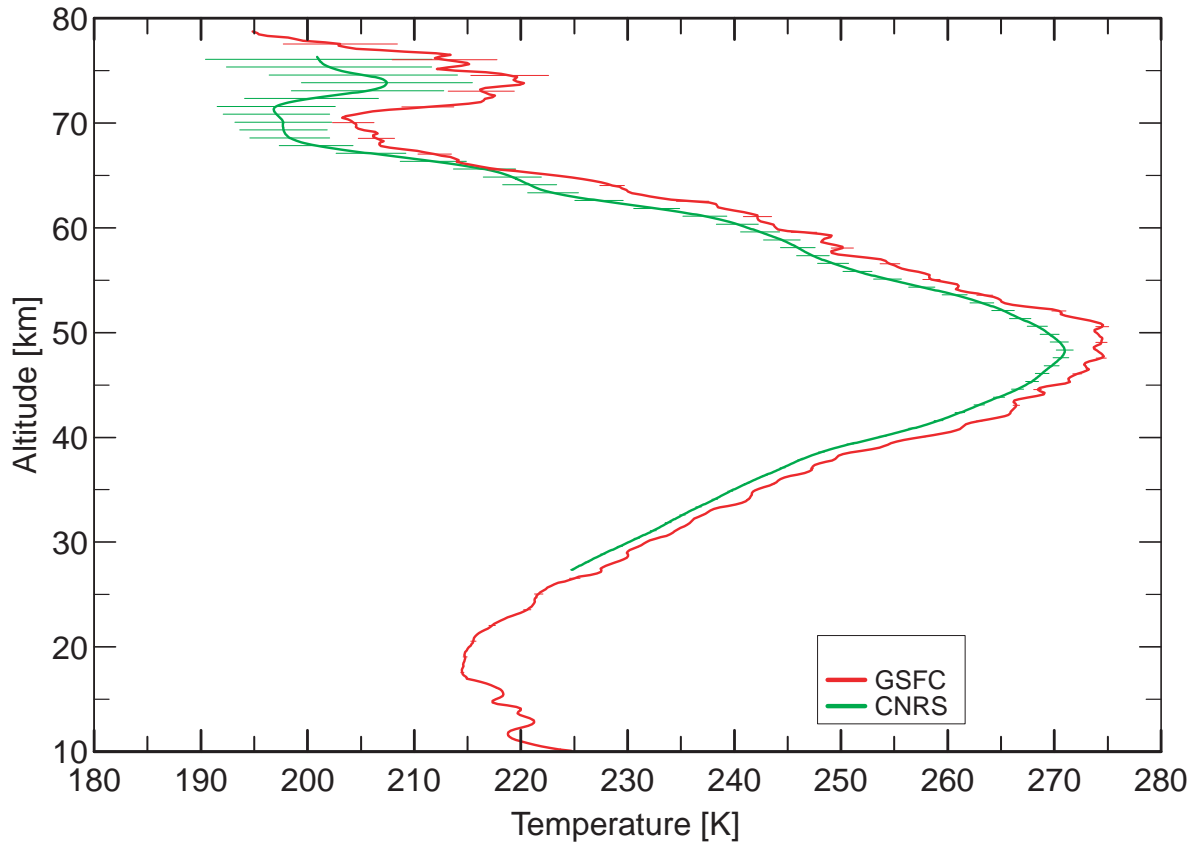

Intercomparison of stratospheric ozone and temperature measurements

G. O. Braathen et al.

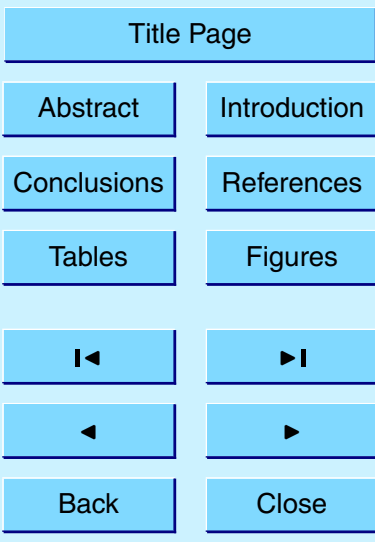

Full Screen / Esc

Fig. 11. Comparison of two temperature lidar profiles recorded during the same night (7 July 1997). The green curve is the CNRS lidar and red curve is the GSFC lidar.

Print Version

Interactive Discussion

(c) EGU 2004 


\section{ACPD}

4, 5303-5344, 2004
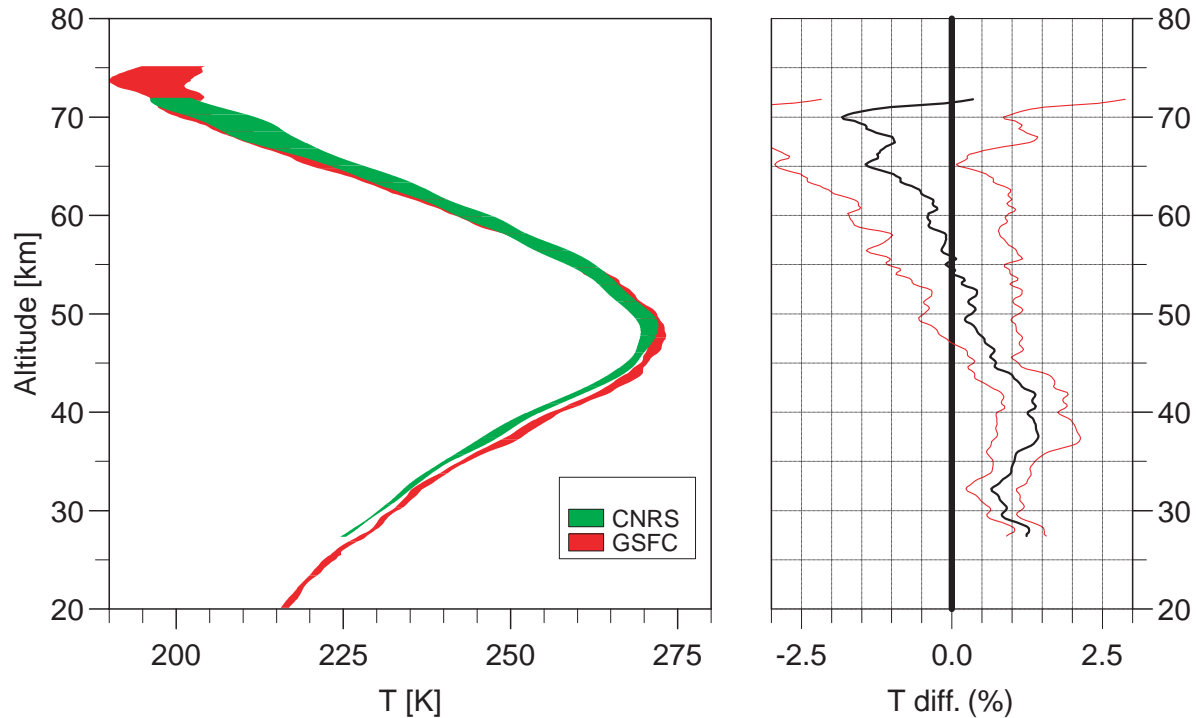

Fig. 12. (Left) Average of 13 coincident temperature profiles from each of the two temperature lidars (red curve, GSFC; green curve, CNRS). The thickness of the red and green curves represent twice the standard deviations of the means (SDOM) of two data sets. (Right) Relative difference between the CNRS and the GSFC mean profiles. The thin red curves represent the difference of the mean plus/minus two times the standard deviation of the difference. See main text for a detailed explanation of the statistical calculations.
Intercomparison of stratospheric ozone and temperature measurements

G. O. Braathen et al.

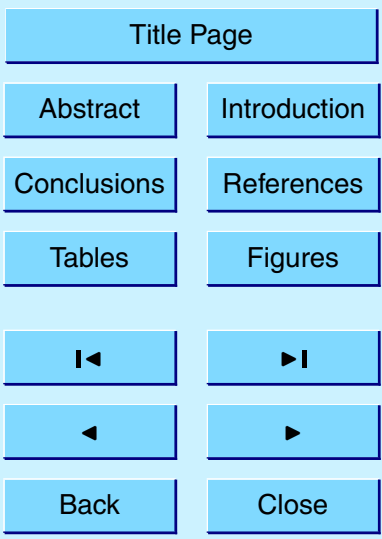

Full Screen / Esc

Print Version

Interactive Discussion 


\section{ACPD}

4, 5303-5344, 2004

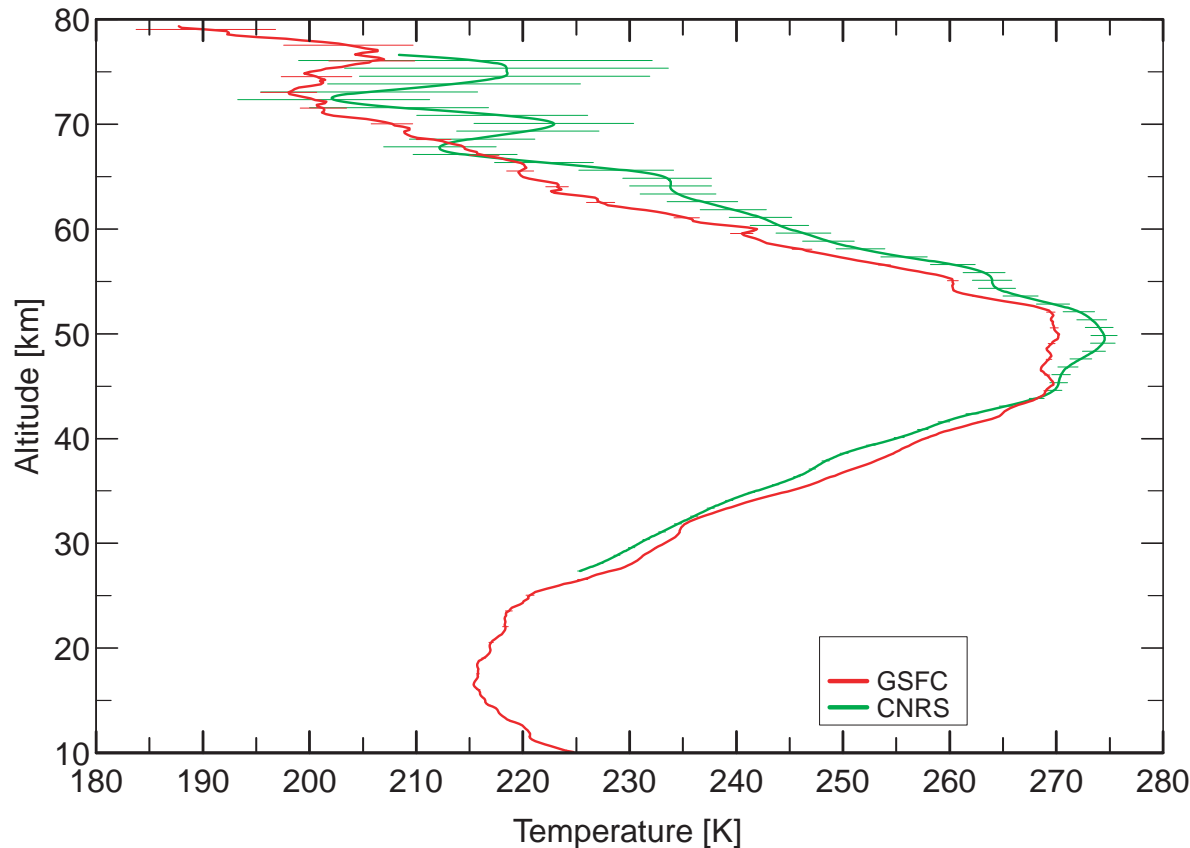

Intercomparison of stratospheric ozone and temperature measurements

G. O. Braathen et al.

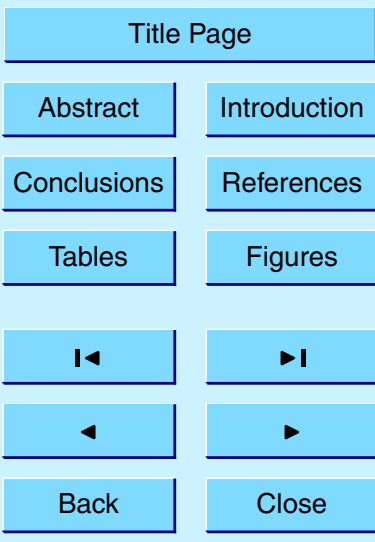

Full Screen / Esc

Fig. 13. Example of pair of temperature profiles where the one profile looks shifted vertically compared to the other profile.These profiles were measured on 11 July 1997.

Print Version

Interactive Discussion

(c) EGU 2004 


\section{ACPD}

4, 5303-5344, 2004
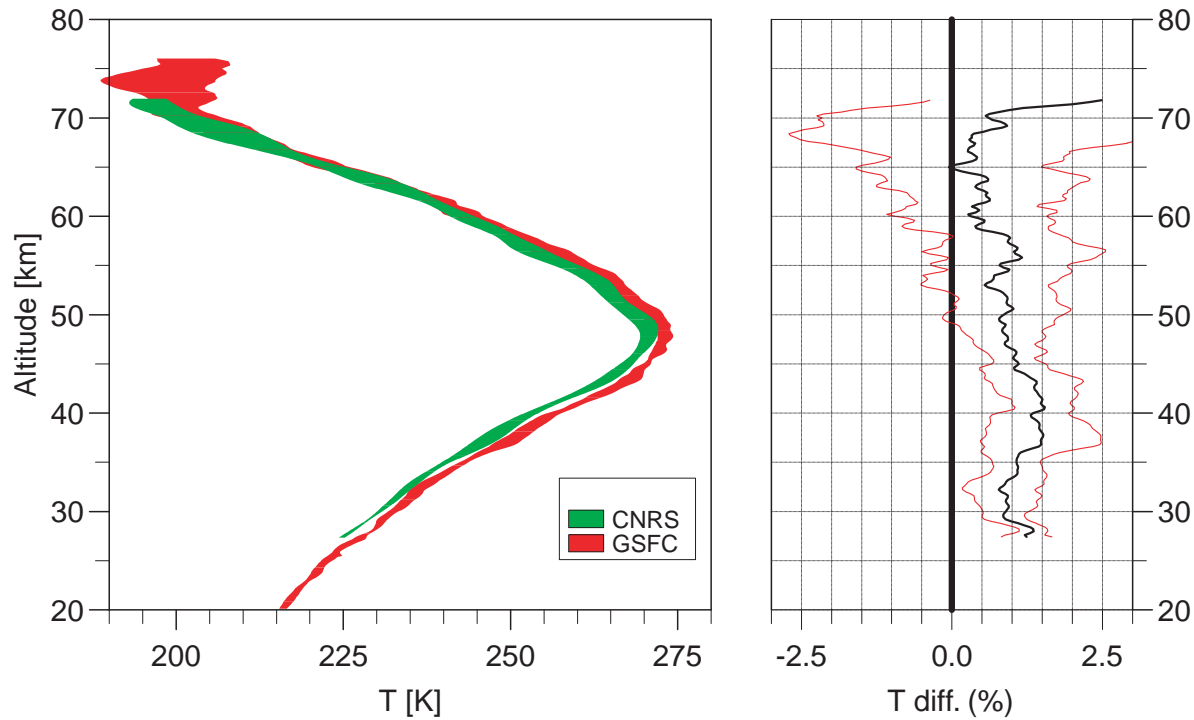

Intercomparison of stratospheric ozone and temperature measurements

G. O. Braathen et al.

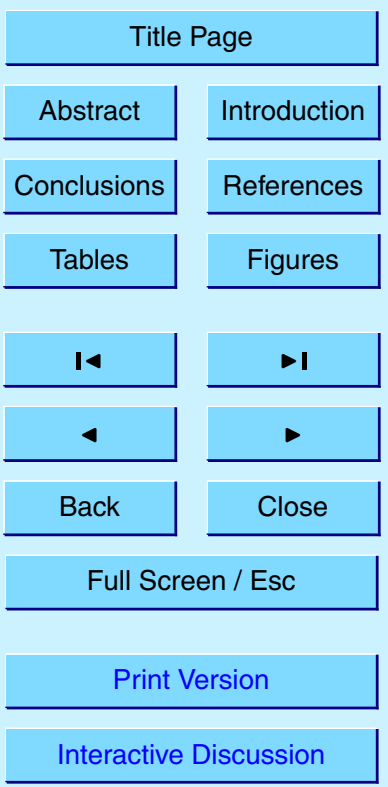

(C) EGU 2004

Fig. 14. Same as Fig. 11, but now the averages are based on measurements made on 1, 5, 6, $7,9,12,13$ and 14 July. 


\section{ACPD}

4, 5303-5344, 2004

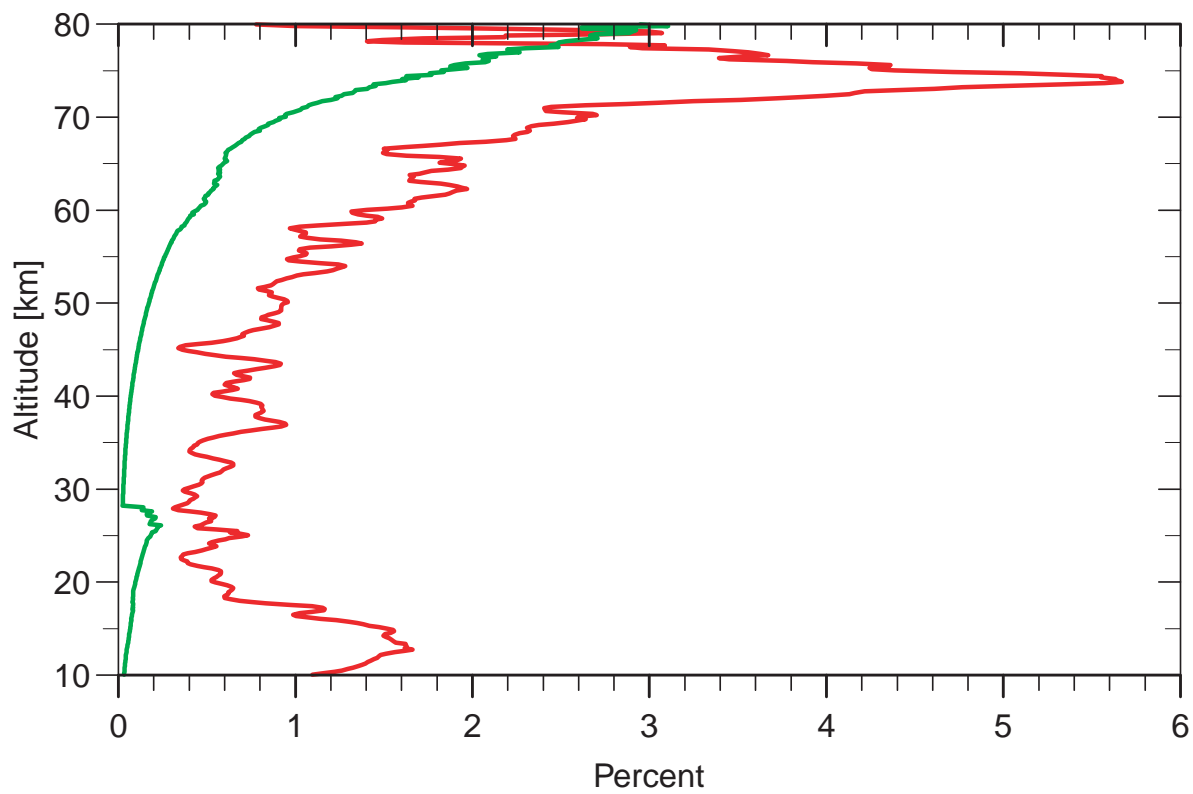

Intercomparison of stratospheric ozone and temperature measurements

G. O. Braathen et al.

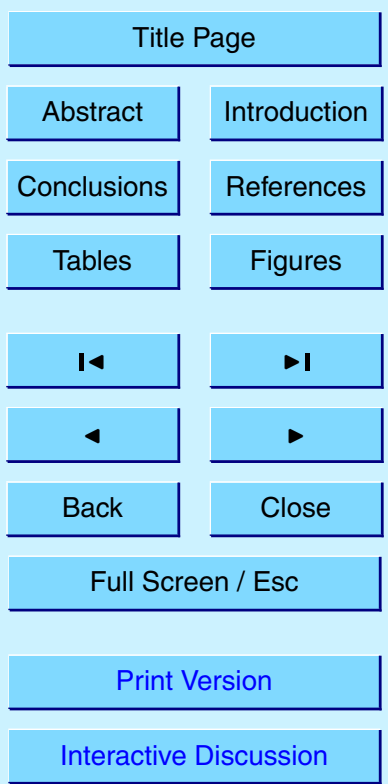

Fig. 15. Relative standard deviation (percent) of the 13 GSFC temperature lidar profiles (red curve) and relative standard deviation based on the instrumental statistical error (green curve). See main text for details of the calculations.

C) EGU 2004 


\section{ACPD}

4, 5303-5344, 2004

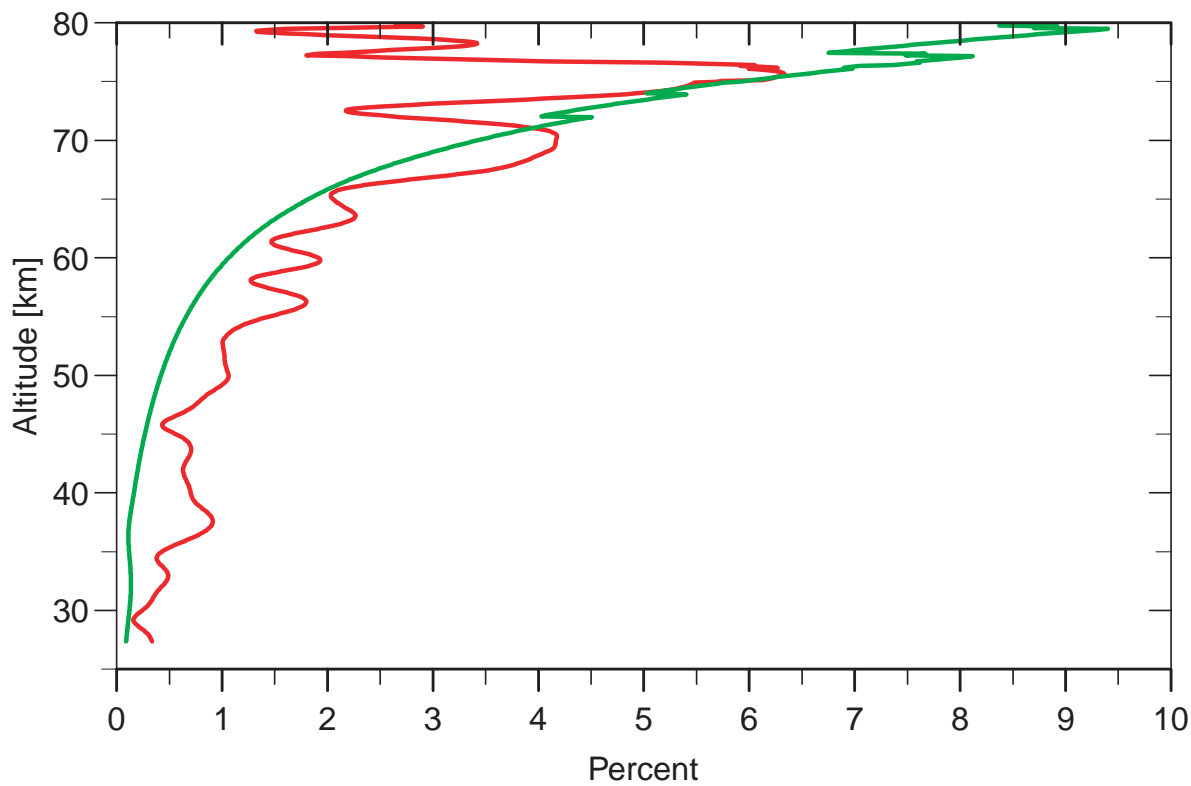

Intercomparison of stratospheric ozone and temperature measurements

G. O. Braathen et al.

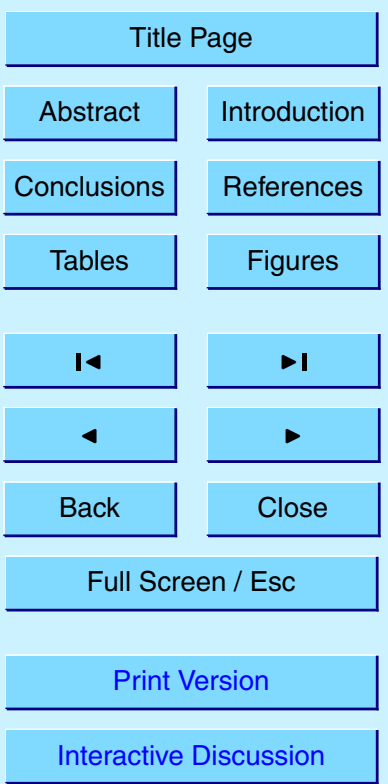

Fig. 16. Relative standard deviation (percent) of the 13 CNRS temperature lidar profiles (red curve) and relative standard deviation based on the instrumental statistical error (green curve). See main text for details of the calculations.

C) EGU 2004 